\title{
Changes in the Urine Proteome in Patients With Advanced Lung Cancer After Different Drug Treatments
}

\section{Yameng Zhang}

Beijing Normal University

\section{Ziqi Heng}

Beijing Normal University

Jing Wei

Beijing Normal University

\section{Yingyi Wang}

Chinese Academy of Medical Sciences \& Peking Union Medical College

Youhe Gao ( $\nabla$ gaoyouhe@bnu.edu.cn )

Beijing Normal University

\section{Research Article}

Keywords: Urine, Proteome, Advanced lung cancer, Pathophysiological changes

Posted Date: November 30th, 2020

DOI: https://doi.org/10.21203/rs.3.rs-109321/v1

License: (c) (1) This work is licensed under a Creative Commons Attribution 4.0 International License. Read Full License 


\section{Changes in the urine proteome in patients with advanced}

\section{2 lung cancer after different drug treatments}

3 Yameng Zhang ${ }^{1}$, Ziqi Heng ${ }^{1}$, Jing Wei ${ }^{1}$, Yingyi Wang ${ }^{2 *} \&$ Youhe Gao ${ }^{1 *}$

4

$5 \quad{ }^{1}$ Gene Engineering Drug and Biotechnology Beijing Key Laboratory, Department of

6 Biochemistry and Molecular Biology, College of Life Sciences, Beijing Normal University,

$7 \quad$ Beijing 100875, China

$8 \quad 2$ Department of Medical Oncology, Peking Union Medical College Hospital, Chinese Academy

9 of Medical Sciences and Peking Union Medical College, Beijing, China

11 Corresponding Author:

12 Youhe Gao

13 No.19 Xinjiekouwai St., Beijing, 100875, China

14 Email address: gaoyouhe@bnu.edu.cn

15

Yingyi Wang

17 No.41 Damucang hutong, Xicheng district, Beijing, 100032, China

18 Email address: waltwyy@163.com

\section{Abstract}

21 Lung cancer is one of the most threatening diseases to human life and health because of its

22 mortality. How to choose more efficient drugs and the appropriate timing of treatment for

23 patients with advanced lung cancer is still a problem. As the urine proteome can sensitively

24 reflect the pathological or physiological changes of the body, it has the potential to reflect the

25 dynamic changes of the body after drug treatment. To investigate the changes in the urine

26 proteome of patients with advanced lung cancer after different drug treatments, urine samples

27 were collected and analyzed at different time points. The changes in the urine proteome from the

28 pretreatment state were different in each patient, although some of them were treated with the

29 same drugs. The changes in the biological processes reflected by the differential urinary proteins 
were consistent with the changes in the clinical manifestations of the patients. This study demonstrates that the pathophysiological changes of patients with advanced lung cancer can be reflected by changes in urinary protein after different drug treatments. In addition, the changes in urinary proteins can reflect the different biological processes in patients after the same drug treatment, and the patients' clinical condition assessment results are consistent with these changes. These findings may provide additional information for clinical treatment. Keywords: Urine; Proteome; Advanced lung cancer; Pathophysiological changes

Introduction

In recent years, lung cancer has become a serious threat to human lives and health because of its rapidly increasing incidence and mortality. It is reported to be the most commonly diagnosed cancer $(11.6 \%)$ and the leading cause of cancer deaths $(18.4 \% \text { of total cancer deaths })^{1}$. In addition, lung cancer is the second most frequent cancer in both sexes combined worldwide, and

43 it is also the most frequent cancer in the Chinese population ${ }^{2,3}$. Among lung cancers, non-smallcell lung cancer (NSCLC) and small-cell lung cancer (SCLC) are the two main histologic classes. NSCLC is the most common subtype, accounting for approximately $83 \%$ of all lung cancers ${ }^{4}$. immunotherapy. The choice of therapeutic modality depends on multiple factors, including the type and stage of the cancer 5 . Platinum-based regimens are the standard of treatment for advanced lung cancer in current clinical treatment, and they had better advantages in the survival

50 rate and symptom control when combined with chemotherapy. However, their clinical

51 effectiveness is affected by cumulative hematotoxicities and neurotoxicities, highlighting the 52 requirement for alternative treatments ${ }^{5}$. In terms of adverse events, carboplatin mostly causes 
thrombocytopenia, and cisplatin mostly causes nausea and vomiting. Therefore, the choice of platinum compounds should take into account the expected toxicity profile, patient comorbidities, and patient preferences ${ }^{6}$. Angiogenesis inhibitors are promising and effective ways to treat lung cancer. For example, bevacizumab, as a commonly used therapeutic drug for lung cancer, can promote tumor cell apoptosis. However, recent studies have found that it has certain toxic side effects in clinical applications, such as hypertension ${ }^{7}$, bleeding $^{8}$, and proteinuria ${ }^{9}$. Among immunotherapies, pembrolizumab is an immune checkpoint inhibitor that is being rapidly developed and is approved as a first-line treatment for advanced NSCLC ${ }^{10}$. However, immunerelated adverse effects caused by immunotherapy can affect various systems, such as abnormal thyroid function, pneumonia, and severe skin reactions ${ }^{11}$. Some patients will have different degrees of resistance after clinical targeted therapy, which further impacts the clinical prognosis and quality of life. Based on these problems, determining the most effective treatment for each patient, the appropriate treatment method and combined application of different methods, and the ideal timing of the treatment as well as providing the best treatment effect and reducing adverse effects are still challenges that cannot be ignored in the treatment of lung cancer. Clinicians should be mindful of these factors when considering therapeutic options for patients.

Urine proteome can sensitively reflect physiological changes in the body. With no regulation of homeostatic mechanisms, urine can accumulate changes throughout the body at a very early stage ${ }^{12}$. Many studies have shown that changes in the urine proteome can provide clues for the early diagnosis of many diseases, such as myocarditis model ${ }^{13}$, Alzheimer model ${ }^{14}$, liver fibrosis mode ${ }^{15}$, glioma mode ${ }^{16}$, lung fibrosis mode $1^{17}$, and chronic pancreatitis model ${ }^{18}$. In addition, the urine proteome can sensitively distinguish more subtle differences. It has been reported that urinary proteins have the potential to differentiate the same tumor cells grown in 
different organs ${ }^{19}$. Urinary proteins can also sensitively reflect the changes caused by very few cells growing in the body ${ }^{20}$. We speculate that the potential of the urine proteome likely remains to be unleashed completely. Theoretically, if urine samples taken at different periods from one person are compared, and that the person had no significant lifestyle changes during that period, the changes in the urine should reflect the person's physiological or pathological changes during this period. The careful analysis of changes in urinary proteins caused by many different drugs with different side effects may provide clues about disease-related pathways and biological processes in the patient, which can aid in choosing the appropriate drugs to avoid adverse side effects $^{21}$.

In this study, we collected urine samples from eight patients with advanced lung cancer after different drug treatments and analyzed them by liquid chromatography-mass spectrometry (LC-MS/MS). Each patient chose their own controls to compare differences in their urine proteome at different stages. This study aims to discover dynamic changes in urinary proteins in patients with advanced lung cancer after different drug treatments and whether the urine proteome has the potential to reflect the pathophysiological changes that are consistent with clinical manifestations. It also further investigates the ability of the urine proteome to differentiate the changes in biological process induced by different drugs.

\section{Results}

Changes in the urine proteome in patients with advanced lung cancer. From October 2018 to June 2019, a total of 23 urine samples were collected and analyzed from 8 patients at different time points after drug treatment, and label-free LC-MS/MS quantification was used to characterize the differential urinary proteins. The number of urinary proteins identified in 8 
patients is shown in Table 1. The collection time of urine samples, medications and clinical manifestations are shown in Tables 2 to 9. The screening conditions were set as follows: fold

101 change $\geq 2$ or $\leq 0.5$; and $P$-value $<0.05$.

102 Table 1 The number of urinary proteins identified in 8 patients.

\begin{tabular}{lllll}
\hline Patient ID & $\begin{array}{l}\text { The number of } \\
\text { total urinary } \\
\text { proteins }\end{array}$ & \multicolumn{4}{l}{$\begin{array}{l}\text { The number of differential urinary proteins identified at } \\
\text { different time points and the percentage in the total } \\
\text { differential urinary protein }\end{array}$} \\
& & T1 & T2 & T3 \\
\hline P1 & 1,448 & $262,55.5 \%$ & $223,47.2 \%$ & $241,51.1 \%$ \\
P2 & 1,534 & $161,32.8 \%$ & $302,61.5 \%$ & $232,47.2 \%$ \\
P3 & 1,049 & $71,100 \%$ & - & - \\
P4 & 1,107 & $315,100 \%$ & - & - \\
P5 & 1,178 & $233,100 \%$ & - & - \\
P6 & 1,838 & $276,32.5 \%$ & $330,38.8 \%$ & $628,73.9 \%$ \\
P7 & 1,215 & $212,100 \%$ & - & - \\
P8 & 1,248 & $194,47.5 \%$ & $329,80.6 \%$ & - \\
\hline
\end{tabular}

- means no urine samples were collected. T1, T2, and T3 mean different collection times of urine samples.

Changes in the urine proteome and functional analysis in patient P1. The urine samples of patient P1 at four time points before and after drug treatment were collected and analyzed. More details about the urine samples and the clinical symptoms of the patient are shown in Table 2. Compared to those seen before drug treatment, a total of 1,448 urinary proteins were identified after treatment. After screening, 472 differential urinary proteins were identified, of which 262,

110223 , and 241 were identified at the three time points, T1, T2 and T3 (Table 1). A Venn diagram

111 showed overlapping differential urinary proteins at the three time points (Fig. 1A). Seventy-four

112 proteins changed continuously at three time points, and 130, 66, and 96 unique differential

113 urinary proteins changed at the T1, T2 and T3 time points, respectively.

115 manifestations of all patients were unknown when the functional analysis of urinary proteins was

116 performed. The differential proteins identified at the T1, T2, and T3 time points were analyzed

117 by the DAVID database and classified based on biological processes. At the three time points, 
118 some biological processes related to immunity and tumor growth changed significantly (Table 2,

119 Fig. 1B). At the T1 time point, complement activation, cellular response to growth factor

120 stimulus, complement activation and classical pathway, cell response to tumor necrosis factor,

121 regulation of immune, innate immune response, antigen processing and presentation, Fc-epsilon

122 receptor signaling pathway, Fc-gamma receptor signaling pathway involved in phagocytosis, and

123 chronic inflammatory response were altered. Compared with that before administration, the

124 immune-related response in the patient changed significantly at the T1 time point. At the T2 time

125 point, the significantly affected biological processes included complement activation,

126 complement activation and classical pathway, Fc-gamma receptor signaling pathway involved in

127 phagocytosis, complement activation and alternative pathway, and immune response. These

128 immune-related response changes significantly in the overall biological process, indicating that

129 after the activation of the immune system, a large number of tumor cells were continuously

130 recognized and killed, which is consistent with the partial response of the evaluation in the

131 patient at this time point. At the T3 time point, complement activation, complement activation

132 and classical pathway, immune response, complement activation and alternative pathway,

133 regulation of complement activation, inflammatory response, and gluconeogenesis were altered,

134 and gluconeogenesis has been reported to be associated with tumor growth ${ }^{22}$. At this point, the

135 evaluation of the patient was stable disease. 
Table 2 The clinical information of patient P2 and the changed biological processes at different time points.

\begin{tabular}{|c|c|c|c|c|c|c|}
\hline $\begin{array}{l}\text { Urine } \\
\text { collection } \\
\text { time }\end{array}$ & $\begin{array}{l}\text { Target } \\
\text { focus } \\
\text { length } \\
(\mathrm{mm})\end{array}$ & $\begin{array}{l}\text { Non- } \\
\text { target } \\
\text { focus }\end{array}$ & $\begin{array}{l}\text { Clinical } \\
\text { manifestations }\end{array}$ & $\begin{array}{l}\text { Treatment } \\
\text { duration }\end{array}$ & Medication use & Biological processes change significantly (in part) \\
\hline Control & 35.2 & Yes & Baseline & None & None & None \\
\hline
\end{tabular}

(2018.12.

11)

T1

(2019.01.

36.4 Yes Stable disease

23)

T2

(2019.04.

29)
Progressive disease

2019.02.2

(firs day); pemetrexed:991mg (first day); cisplatin: $149 \mathrm{mg}$ (first day)

2019.03.29 Sintilimab:200mg; pemetrexed:991mg (first day)

day); pemetrexed:991mg

$\begin{array}{ll}\text { (first day); } & \text { cell-cell adhesion, cell recognition, serine family amino acid } \\ \text { cisplatin:149mg (first day) } & \text { biosynthetic process, neutrophil aggregation, positive regulation of }\end{array}$ inflammatory response

T2: platelet degranulation, cell adhesion, carbohydrate metabolic process, proteolysis, gluconeogenesis, NIK/NF-kappaB signaling, proteolysis involved in cellular protein catabolic process, Fc-epsilon receptor signaling pathway, Fc-gamma receptor signaling pathway involved in phagocytosis, tumor necrosis factor-mediated signaling pathway, Wnt signaling pathway, planar cell polarity pathway, regulation of immune system process, regulation of immune response, methionine biosynthetic process, negative regulation of angiogenesis, cell recognition, cell-cell adhesion, fructose metabolic process, complement activation, positive regulation of canonical Wnt signaling pathway, glycolytic process, regulation of inflammatory response, complement activation, classical pathway, serine family amino acid biosynthetic process, L-methionine salvage

T3: proteolysis, receptor-mediated endocytosis, cell adhesion, platelet degranulation, cellular protein metabolic process, Fc-gamma receptor signaling pathway involved in phagocytosis, regulation of immune system process, complement activation and classical pathway, Fcepsilon receptor signaling pathway, proteolysis involved in cellular protein catabolic process, complement activation, Wnt signaling pathway, planar cell polarity pathway, acute inflammatory response, tumor necrosis factor-mediated signaling pathway, leukocyte migration, immune response, L-methionine salvage, carbohydrate metabolic process, negative regulation of angiogenesis 
A

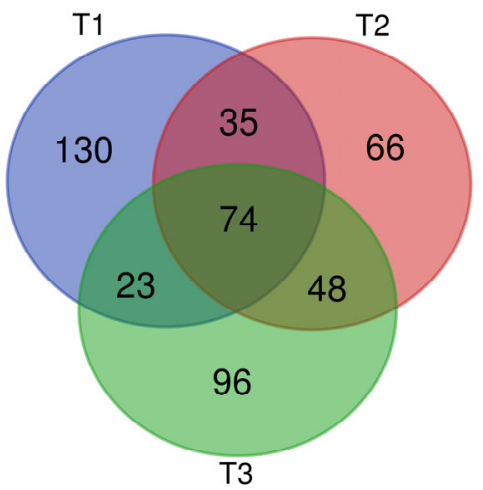

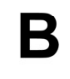

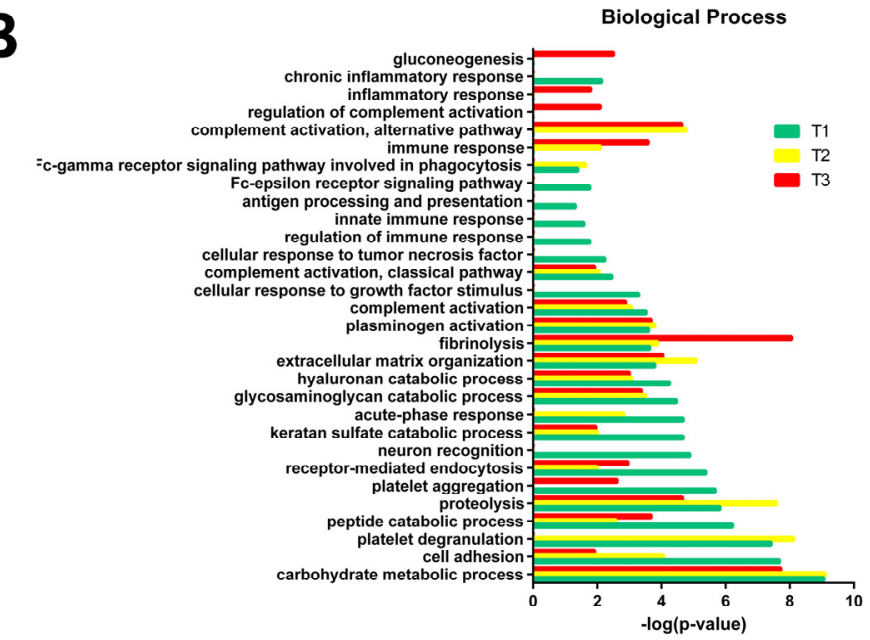

138

139 Fig. 1 Proteomic analysis of urine samples in patient P1. A, overlap evaluation of the differential proteins

141 points, $\mathrm{T} 1, \mathrm{~T} 2$ and $\mathrm{T} 3$.

142

143 Changes in the urine proteome and functional analysis in patient $\mathbf{P 2}$. The urine samples of

144 patient P2 at four time points before and after drug treatment were collected and analyzed. More

145 details about the urine samples and the clinical symptoms of the patients are shown in Table 1.

146 Compared to those seen before drug treatment, a total of 1,534 urinary proteins were identified.

147 After screening, 491 differential urinary proteins were identified, of which 161, 302 and 232

148 were identified at the three time points, T1, T2, and T3, respectively (Table 1). A Venn diagram

149 showed overlapping differential urinary proteins at the three time points (Figure 2A). Twenty-

150 seven proteins changed continuously at three time points, and 79, 146, and 89 unique differential

151 urinary proteins changed at the T1, T2 and T3 time points, respectively. 

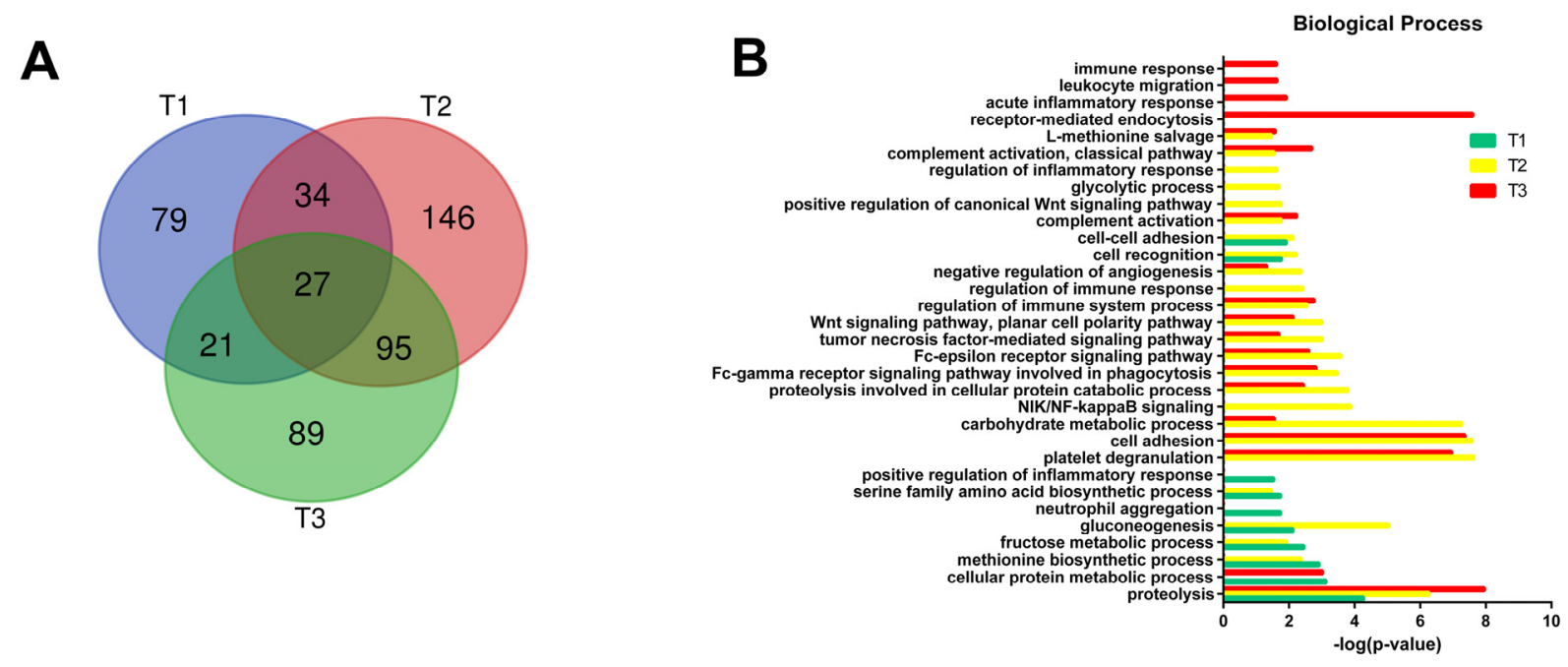

153 Fig. 2 Proteomic analysis of urine samples in patient P2. A, overlap evaluation of the differential proteins

154 identified at three time points, T1, T2, and T3. B, biological processes of differential proteins at three time 155 points $\mathrm{T} 1, \mathrm{~T} 2$ and $\mathrm{T} 3$.

The differential proteins identified at the $\mathrm{T} 1, \mathrm{~T} 2$, and $\mathrm{T} 3$ time points were analyzed by the DAVID database and classified based on biological processes. Changes in biological processes are shown in Table 3 and Figure 2B. At the T1 time point, processes related to proteolysis,

160 cellular protein metabolic process, methionine biosynthetic process, fructose metabolic process,

161 gluconeogenesis, serine family amino acid biosynthetic process, neutrophil aggregation and

162 positive regulation of inflammatory response changed significantly, and proteolysis continuously

163 changed significantly at each of the three time points. Compared with those before

164 administration, few immune responses in patient $\mathrm{P} 2$ changed, and the biological processes

165 associated with tumor growth changed more significantly. At this point, the evaluation of the

166 patient was stable disease. Some of these changed biological processes have been reported in

167 cancer, such as neutrophil aggregation, which is involved in many processes, including acute 
168 injury and repair, chronic inflammatory processes, cancer, and autoimmunity ${ }^{23}$. It has been

169 reported that methionine biosynthetic process is related to cancer, as many kinds of cancer cells

170 require exogenous methionine to survive ${ }^{24}$. The abnormal dependence of cancer cells on

171 methionine leads to methionine limitation as a potential treatment strategy ${ }^{25}$. Serine, as an

172 important one-carbon donor of the folic acid cycle, can play an antioxidant role because many

173 kinds of cancer cells are highly dependent on $\mathrm{it}^{26}$.

174 At the T2 and T3 time points, the biological processes that commonly changed included

175 platelet degranulation, cell adhesion, carbohydrate metabolism, proteolysis involved in cellular

176 protein catabolic process, Fc-gamma receptor signaling pathway involved in phagocytosis, Fc-

177 epsilon receptor signaling pathway, tumor necrosis factor-mediated signaling pathway, Wnt

178 signaling pathway and planar cell polarity pathway, regulation of immune system process,

179 negative regulation of angiogenesis, cell recognition, cell adhesion, complement activation,

180 complement activation and classical pathway, and L-methionine salvage. Except for the common

181 biological processes, the changed biological processes at the T2 time point included NIK/NF-

182 kappaB signaling, regulation the immune response, positive regulation of canonical Wnt

183 signaling pathway, glycolysis process, and regulation of inflammatory response. The changed

184 biological processes at the T3 time point included receptor-mediated endocytosis, acute

185 inflammatory response, leukocyte migration, and immune response. Some biological processes

186 have been reported to be associated with tumors, for example, tumor cells usually show a

187 reduction in cell-to-cell and/or cell-matrix adhesions, and there is increasing evidence that the

188 reduction in cell adhesion is associated with tumor invasion and metastasis ${ }^{27} . \mathrm{NF}-\kappa \mathrm{B}$ has anti-

189 inflammatory effects in vivo ${ }^{28}$; (3) Wnt signaling abnormalities are generally considered to be 
190 key factors that trigger and maintain many cancers by affecting cancer stem cells (CSCs) ${ }^{29}$.

191 Angiogenesis is considered a common feature of tumorigenesis ${ }^{30}$.

192 Those changes in biological processes that are negatively related to tumor growth may be

193 related to the use of chemotherapy drugs in patient P2. A large number of immune-related

194 biological processes were increased at two time points, which may be related to the use of

195 sintilimab. However, in the overall biological processes, the changes in biological processes

196 negatively related to tumor growth changes were less significant, while those related to the

197 immune system appeared later. At this point, the evaluation of the patient was progressive

198 disease. It may be that the combination of these drugs used in patient P2 has no good

199 therapeutically effective.

201 Changes in the urine proteome and functional analysis in patient P3. The urine samples of

202 patient P3 at two time points before and after drug treatment were collected and analyzed. More 203 details about the urine samples and the clinical symptoms of the patient are shown in Table 4.

204 Compared to those seen before drug treatment, a total of 1,049 urinary proteins were identified.

205 After the screening, 71 differential urinary proteins were identified (Table 1).

206 Functional enrichment analysis was performed on the identified differential urinary proteins by 207 using the DAVID database. Changes in biological processes are shown in Table 4 and Fig. 3.

208 Processes related to platelet degranulation, platelet aggregation, blood coagulation and fibrin clot

209 formation, blood coagulation, wound healing and spreading of cells significantly changed, which

210 may be related to the clinical manifestations in patient P3, such as cough and hemoptysis before

211 treatment. After treatment, these symptoms were relieved. Changes in immune-related reactions

212 include positive regulation of NF-kappaB transcription factor activity, positive regulation of 
213 Table 3 The clinical information of patient P1 and the changed biological processes at different time points.

\begin{tabular}{lllll}
\hline $\begin{array}{l}\text { Urine } \\
\text { collection time }\end{array}$ & $\begin{array}{l}\text { Clinical } \\
\text { manifest- } \\
\text { ations }\end{array}$ & $\begin{array}{l}\text { Treatment } \\
\text { duration }\end{array}$ & Medication use & Biological processes change significantly (in part) \\
\hline $\begin{array}{l}\text { Control } \\
(2018.11 .25)\end{array}$ & $\begin{array}{l}\text { Baseline } \\
\text { T1 }\end{array}$ & None & None & None \\
$(2019.01 .08)$ & $\begin{array}{l}\text { Stable } \\
\text { disease }\end{array}$ & None & None & $\begin{array}{l}\text { T1: carbohydrate metabolic process, cell adhesion, platelet degranulation, peptide } \\
\text { catabolic process, proteolysis, platelet aggregation, receptor-mediated endocytosis, } \\
\text { neuron recognition, keratan sulfate catabolic process, acute-phase response, } \\
\text { glycosaminoglycan catabolic process, hyaluronan catabolic process, extracellular } \\
\text { matrix organization, fibrinolysis, plasminogen activation, complement activation, } \\
\text { cellular response to growth factor stimulus, complement activation, classical pathway, } \\
\text { cellular response to tumor necrosis factor, chronic inflammatory response, regulation of } \\
\text { immune response, Fc-epsilon receptor signaling pathway, innate immune response, Fc- } \\
\text { gamma receptor signaling pathway involved in phagocytosis, antigen processing and } \\
\text { presentation }\end{array}$
\end{tabular}

T2 Partial

(2019.02.21) response

$\mathrm{T} 3$

Stable

(2019.04.10) disease
2019.01 .23

Pemetrexed:930

$\operatorname{mg}($ first

day);cisplatin:40

$\mathrm{mg}$ (first day to

third

day); bevacizuma

b:500mg(first

day)

2019.04.09

Pemetrexed:930

$\mathrm{mg}($ first day);

bevacizumab:50

$0 \mathrm{mg}$ (first day) presentation

T2: carbohydrate metabolic process, platelet degranulation, proteolysis, extracellula matrix organization, complement activation and alternative pathway, cell adhesion,

fibrinolysis, plasminogen activation, glycosaminoglycan catabolic process, hyalur
catabolic process, complement activation, acute-phase response, peptide catabolic process, immune response, complement activation and classical pathway, keratan

sulfate catabolic process, receptor-mediated endocytosis, Fc-gamma receptor signaling pathway involved in phagocytosis

T3: fibrinolysis, carbohydrate metabolic process, proteolysis, complement activation and alternative pathway, extracellular matrix organization, plasminogen activation, peptide catabolic process, immune response, glycosaminoglycan catabolic process, hyaluronan catabolic process, receptor-mediated endocytosis, complement activation, platelet aggregation, gluconeogenesis, regulation of complement activation, keratan sulfate catabolic process, cell adhesion, complement activation and classical pathway, inflammatory response 
215 inflammatory response, neutrophil aggregation, and leukocyte migration involved in

216 inflammatory response. Other biological processes, such as cell adhesion and the positive

217 regulation of nitric oxide biosynthesis, may be related to tumors. It has been reported that nitric

218 oxide has different effects on tumors, as it can either stimulate the growth of tumor cells or

219 promote their death depending on its source ${ }^{31}$.

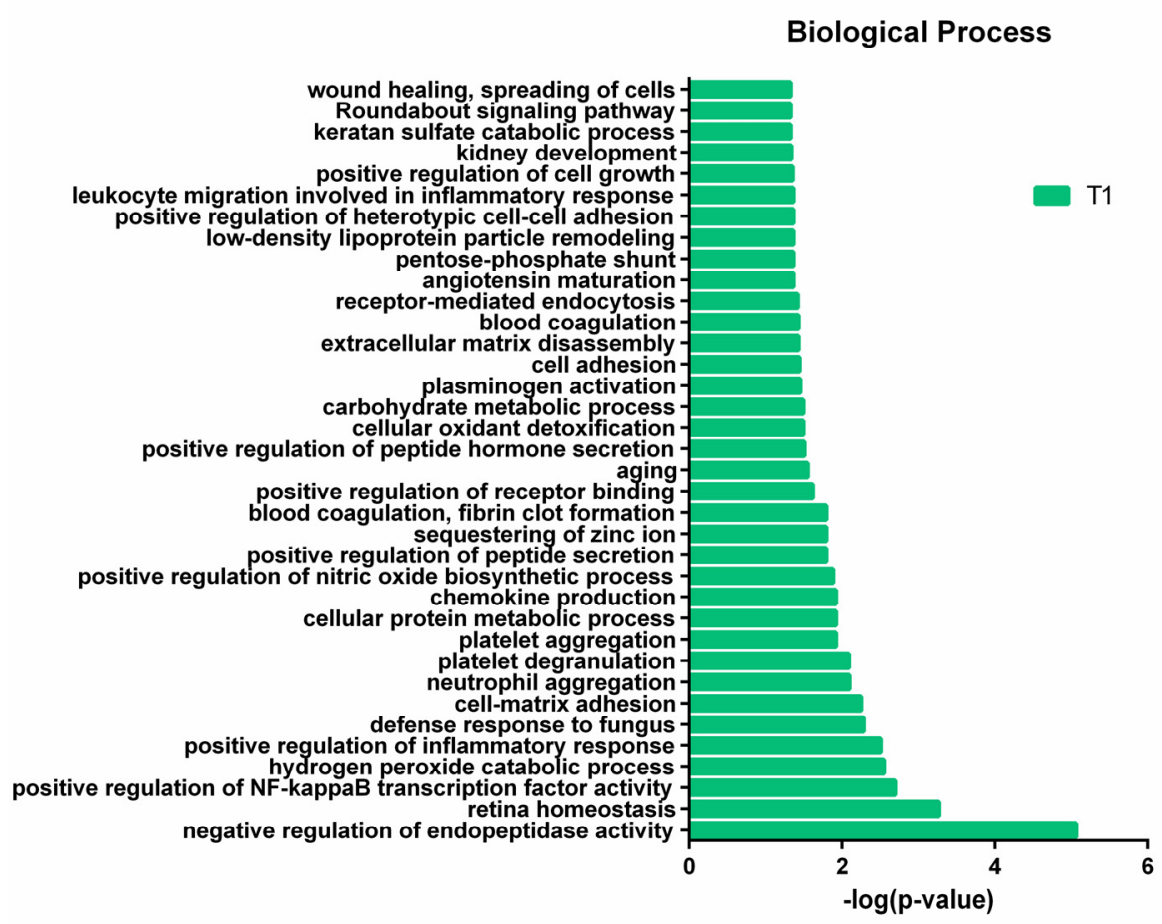

221 Fig. 3 Biological processes of differential proteins in patient P3.

During disease progression in patient $\mathrm{P} 3$, the biological processes related to vigorous tumor growth activities, such as glycolysis and gluconeogenesis, did not change significantly. The results indicate that pembrolizumab had a certain effect in patient P3. This is consistent with the evaluation as stable disease, and the efficacy of the drug may require follow-up observation. 
230 Table 4. The clinical information of patient P3 and the changed biological processes.

\begin{tabular}{|c|c|c|c|c|}
\hline $\begin{array}{l}\text { Urine } \\
\text { collection } \\
\text { time }\end{array}$ & $\begin{array}{l}\text { Clinical } \\
\text { manifestations }\end{array}$ & $\begin{array}{l}\text { Treatment } \\
\text { duration }\end{array}$ & $\begin{array}{l}\text { Medication } \\
\text { use }\end{array}$ & $\begin{array}{l}\text { Biological processes change significantly (in } \\
\text { part) }\end{array}$ \\
\hline $\begin{array}{l}\text { Control } \\
(2018.12 .25)\end{array}$ & Baseline & None & None & None \\
\hline $\begin{array}{l}\text { T1 } \\
(2019.02 .22)\end{array}$ & Stable disease & 2019.02 .02 & $\begin{array}{l}\text { Pembrolizu } \\
\text { mab:200mg( } \\
\text { first day) }\end{array}$ & $\begin{array}{l}\text { T1: negative regulation of endopeptidase } \\
\text { activity, retina homeostasis, positive regulation } \\
\text { of NF-kappaB transcription factor activity, } \\
\text { hydrogen peroxide catabolic process, positive } \\
\text { regulation of inflammatory response, defense } \\
\text { response to fungus, cell-matrix adhesion, } \\
\text { neutrophil aggregation, platelet degranulation, } \\
\text { platelet aggregation, cellular protein metabolic } \\
\text { process, chemokine production, positive } \\
\text { regulation of nitric oxide biosynthetic process, } \\
\text { positive regulation of peptide secretion, } \\
\text { sequestering of zinc ion, blood coagulation and } \\
\text { fibrin clot formation, cell adhesion, blood } \\
\text { coagulation, leukocyte migration involved in } \\
\text { inflammatory response, wound healing and } \\
\text { spreading of cells }\end{array}$ \\
\hline
\end{tabular}

Changes in the urine proteome and functional analysis in patient $\mathbf{P 4}$. The urine samples of

233 patient P4 at two time points before and after drug treatment were collected and analyzed. More

234 details about the urine samples and the clinical symptoms of the patient are shown in Table 5.

235 Compared to before drug treatment, a total of 1,107 urinary proteins were identified. After the

236 screening, 315 differential urinary proteins were identified (Table 1).

237 The differential proteins were analyzed by the DAVID database and classified based on

238 biological processes. Changes in biological processes are shown in Table 5 and Fig. 4. Compared

239 with patient P3, who also had only one time point and was treated with the same medication,

240 patient P4 had more differential proteins and more changes in biological processes. This

241 indicates that patient P4 was more affected by the drug, pembrolizumab, than patient P3. The

242 biological processes with significant changes included a large number of immune response 
243 processes, such as complement activation and classical pathways, acute phase response,

244 complement activation, regulation of complement activation, complement activation and

245 alternative pathway, innate immune response, and regulation of immune system process. In

246 addition, after treatment with pembrolizumab, the impact of the immune response occupies an

247 important position in the change of the overall biological processes. Some biological processes

248 have been reported to be related to tumors. In addition to those biological processes that were

249 described in the previous patients above, such as cell adhesion, platelet degranulation, and

250 proteolysis, vitamin A metabolic processes also play an important role because of the ability of

251 retinoids and their synthetic derivatives to regulate cell growth, induce cell differentiation, and

252 apoptosis. Vitamin A has become a recognized anticancer therapy ${ }^{32}$. Fibrin promotes cell

253 migration by providing a matrix for tumor cell migration and interacting with adhesion

254 molecules and integrins. Fibrinolytic components have different effects on tumors, including

255 promoting tumor cell adhesion to the extracellular matrix and cell proliferation and increasing

256 the survival of tumor cells ${ }^{33}$. On the other hand, the biological processes that are positively

257 related to tumor growth changed to a lesser degree than those negatively related to tumor growth.

258 Although the number of changed biological processes in patient P4 is greater than that in patient

$259 \mathrm{P} 3$, the number of biological processes that are positively related to tumor growth was not been

260 significantly increased. This indicates that the differential proteins are more affected by the

261 immune response.

262 The changes in the biological processes indicate that the changes reflected by urinary

263 protein are consistent with clinical manifestations, and the use of pembrolizumab is better for

264 this patient. 
Biological Process

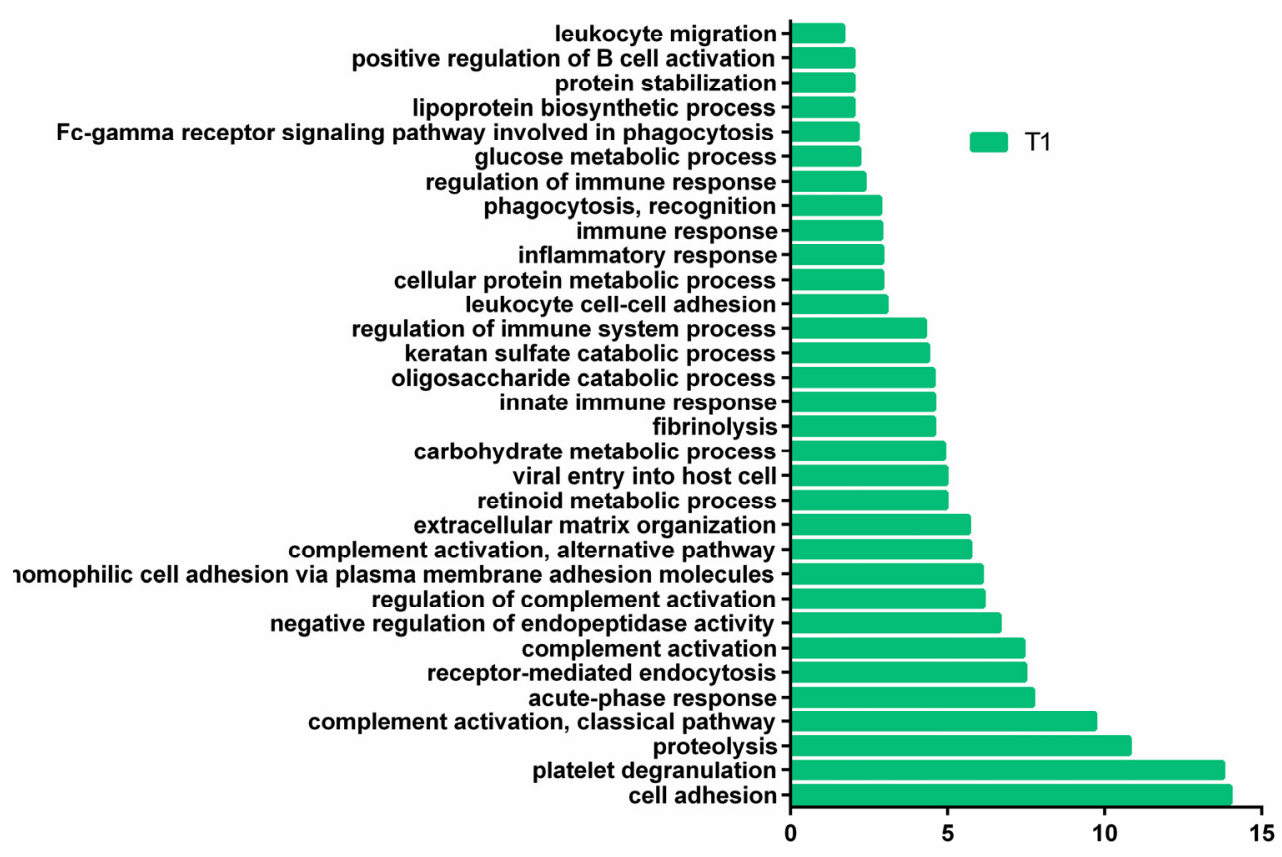

Fig. 4 Biological processes of differential proteins in patient $\mathrm{P} 4$.

269 Table 5. The clinical information of patient $\mathrm{P} 4$ and the changed biological processes.

\begin{tabular}{|c|c|c|c|c|}
\hline $\begin{array}{l}\text { Urine } \\
\text { collection } \\
\text { time }\end{array}$ & $\begin{array}{l}\text { Clinical } \\
\text { manifestations }\end{array}$ & $\begin{array}{l}\text { Treatment } \\
\text { duration }\end{array}$ & $\begin{array}{l}\text { Medication } \\
\text { use }\end{array}$ & Biological processes change significantly (in part) \\
\hline $\begin{array}{l}\text { Control } \\
(2019.01 .0 \\
4)\end{array}$ & Baseline & None & None & None \\
\hline $\begin{array}{l}\text { T1 } \\
(2019.06 .2 \\
8)\end{array}$ & Partial response & 2019.06.17 & $\begin{array}{l}\text { Pembrolizu- } \\
\text { mab: } \\
\text { 200mg (first } \\
\text { day) }\end{array}$ & $\begin{array}{l}\text { T1: cell adhesion, platelet degranulation, } \\
\text { proteolysis, complement activation and classical } \\
\text { pathway, acute-phase response, receptor-mediated } \\
\text { endocytosis, complement activation, negative } \\
\text { regulation of endopeptidase activity, regulation of } \\
\text { complement activation, homophilic cell adhesion } \\
\text { via plasma membrane adhesion molecules, } \\
\text { complement activation and alternative pathway, } \\
\text { extracellular matrix organization, retinoid } \\
\text { metabolic process, viral entry into host cell, } \\
\text { carbohydrate metabolic process, innate immune } \\
\text { response, regulation of immune system process, } \\
\text { leukocyte cell-cell adhesion, inflammatory } \\
\text { response, immune response, phagocytosis and } \\
\text { recognition, glucose metabolic process, Fc-gamma } \\
\text { receptor signaling pathway involved in } \\
\text { phagocytosis }\end{array}$ \\
\hline
\end{tabular}


271 Changes in the urine proteome and functional analysis in patient P5. The urine samples of

272 patient P5 at two time points before and after drug treatment were collected and analyzed. More

273 details about the urine samples and the clinical symptoms of the patient are shown in Table 6.

274 Compared to those seen before drug treatment, a total of 1,178 urinary proteins were identified.

275 After the screening, 233 differential urinary proteins were identified (Table 1).

276 Functional enrichment analysis was performed on the identified differential urinary proteins

277 by using the DAVID database. Changes in biological processes are shown in Table 6 and Fig. 5.

278 Patient P5 also had many differential proteins that were the same as those in patient P4. In terms

279 of biological processes with significant changes, a large number of catabolic processes that may

280 be related to tumors changed significantly, including glycosphingolipid metabolic process,

281 chondroitin sulfate catabolic process, carbohydrate metabolic process, proteolysis,

282 glycosphingolipid metabolic process, glycosaminoglycan catabolic process, retinoid metabolic

283 process, cellular protein metabolic process, oligosaccharide catabolic process, and fibrinolysis.

284 Although there are many changed biological processes, there are fewer biological processes

285 related to immune response than to other signaling processes. The significance of changes in

286 immune-related processes, such as acute phase response, complement activation and alternative

287 pathway, regulation of complement activation, and innate immune response was lower. One

288 possible reason is related to medication use. 


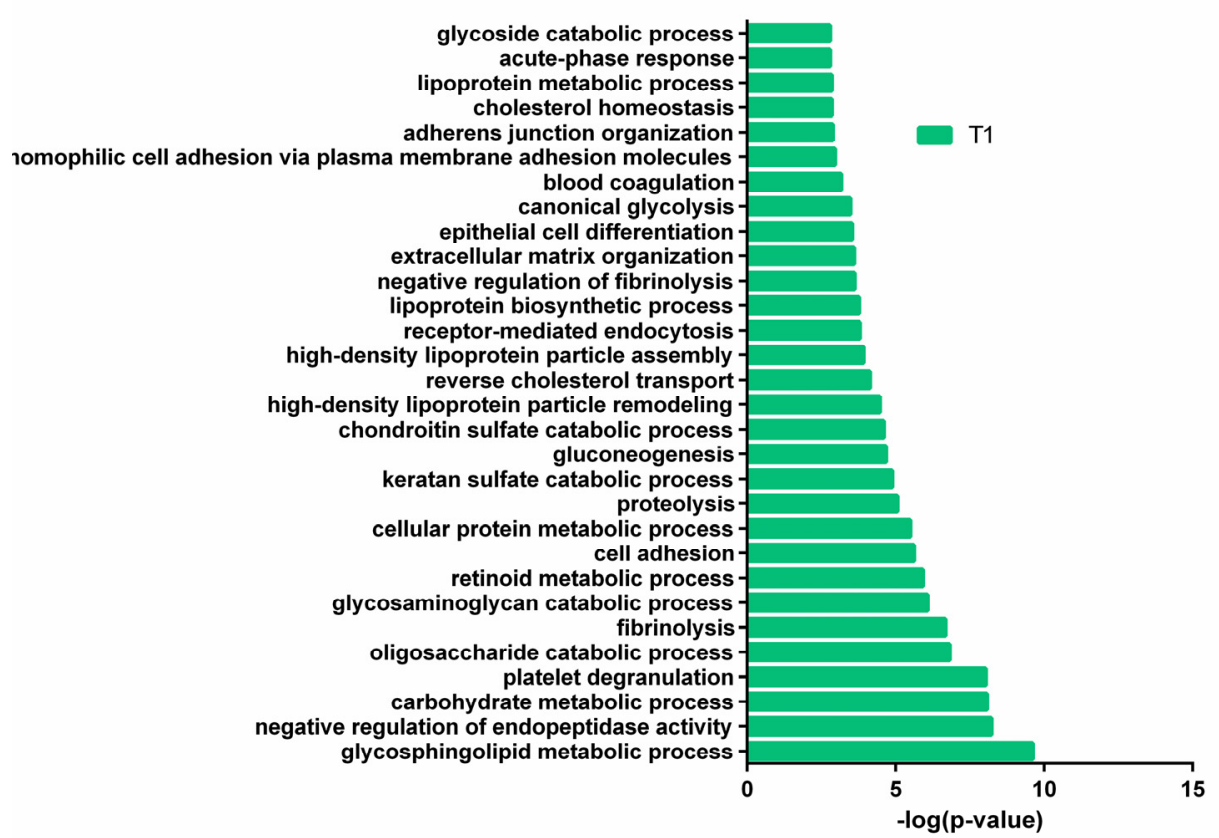

Fig. 5 Biological processes of differential proteins in patient P5.

292 Table 6. The clinical information of patient P5 and the changed biological processes.

\begin{tabular}{lllll}
\hline $\begin{array}{l}\text { Urine } \\
\text { collection }\end{array}$ & $\begin{array}{l}\text { Clinical } \\
\text { manifestations }\end{array}$ & $\begin{array}{l}\text { Treatment } \\
\text { duration }\end{array}$ & Medication use & $\begin{array}{l}\text { Biological processes change } \\
\text { significantly (in part) }\end{array}$ \\
\hline
\end{tabular}

time

Control None None None None

(2018.12.21)

T1

(2019.03.19)
Stable disease 2019.02.19 cisplatin:50mg (first day),40mg (second day to third day)
T1: glycosphingolipid metabolic process, negative regulation of endopeptidase activity, carbohydrate metabolic process, platelet degranulation, oligosaccharide catabolic process, fibrinolysis, glycosaminoglycan catabolic process, retinoid metabolic process, cell adhesion, cellular protein metabolic process, proteolysis, keratan sulfate catabolic process, gluconeogenesis, chondroitin sulfate catabolic process, canonical glycolysis, blood coagulation, homophilic cell adhesion via plasma membrane adhesion molecules, adherens junction organization, cholesterol homeostasis, lipoprotein metabolic process, acutephase response, glycoside catabolic process 
Based on the changes in biological processes, the combined treatment of etoposide and cisplatin used in this patient had an effect. At this time, the patient was evaluated as having stable disease, and the efficacy of the drugs may require follow-up observation.

Changes in the urine proteome and functional analysis in patient P6. The urine samples of patient P6 at four time points before and after drug treatment were collected and analyzed. More details about the urine samples and the clinical symptoms of the patient are shown in Table 7. Compared to those seen before drug treatment, a total of 1,838 urinary proteins were identified. After screening, 850 differential urinary proteins were identified, of which 276, 330 and 628 were identified at the three time points, T1, T2 and T3 (Table 1). A Venn diagram showed overlapping differential urinary proteins at the three time points (Fig. 6A). Eight-six proteins changed continuously at each of the three time points, and 84, 109, and 359 unique differential urinary proteins changed at the $\mathrm{T} 1, \mathrm{~T} 2$ and $\mathrm{T} 3$ time points, respectively.

The differential proteins identified at the $\mathrm{T} 1, \mathrm{~T} 2$, and $\mathrm{T} 3$ time points were analyzed by the DAVID database and classified based on biological processes. Changes in biological processes are shown in Table 7 and Fig. 6B. Some common biological processes changed at the three time points, including platelet degranulation, regulation of complement activation, complement activation and alternative pathway, proteolysis, negative regulation of endopeptidase activity, complement activation, cell adhesion, glycosaminoglycan catabolic process, blood coagulation, complement activation and classical pathway, negative regulation of cell adhesion, cellular amino acid metabolic process, acute phase response, leukocyte migration, cell-cell adhesion, metabolic processes, carbohydrate metabolic process, and oxidation-reduction process. These changed biological processes included many processes related to the immune response and tumor 
316 growth. In addition to those biological processes affected in the other patients, this patient

317 showed some affected biological processes involving tumor growth; for example, tumors will

318 reprogram nutrient acquisition and metabolic pathways to meet the bioenergy, biosynthetic, and

319 redox demands of malignant cells ${ }^{34}$. As some metabolic characteristics are altered in many types

320 of cancer cells, altered metabolism is often considered a hallmark of cancer ${ }^{35,36}$. At the T1 time

321 point, immune-related biological processes, such as the regulation of complement activation,

322 complement activation and alternative pathway, complement activation, regulation of immune

323 response, and complement activation and classical pathway, changed significantly, indicating

324 that immune system function was activated. At the T2 time point, with the activation of the

325 immune system, biological processes such as the regulation of complement activation, leukocyte

326 migration, complement activation and alternative pathway, and tumor necrosis factor-mediated

327 signaling pathway changed significantly. Glycolysis and gluconeogenesis, which are related to

328 tumor growth, were also affected. At the T3 time point, the number of differential proteins

329 increased significantly compared with those seen at the other two time points, and some

330 metabolic decomposition processes, glycolysis and gluconeogenesis, were significantly affected.

331 The immune response-related processes continued to be identified at the same time. 
332 Table 7. The clinical information of patient P6 and the changed biological processes at different time points.

\begin{tabular}{|c|c|c|c|c|c|c|}
\hline $\begin{array}{l}\text { Urine } \\
\text { collection } \\
\text { time }\end{array}$ & $\begin{array}{l}\text { Target } \\
\text { focus } \\
\text { length }\end{array}$ & $\begin{array}{l}\text { Non- } \\
\text { targe } \\
\text { focus }\end{array}$ & $\begin{array}{l}\text { Clinical } \\
\text { manifestations }\end{array}$ & $\begin{array}{l}\text { Treatment } \\
\text { duration }\end{array}$ & Medication use & Biological processes change significantly (in part) \\
\hline
\end{tabular}

\begin{tabular}{llllll}
\multicolumn{1}{l}{$(\mathrm{mm})$} & & & \\
\hline $\begin{array}{l}\text { Control } \\
(2018.10 .28)\end{array}$ & & & Yes Baseline & None & None
\end{tabular}

T1

60.7 Yes Stable disease

2018.11 .22

Pemetrexed:881 complement activation and alternative pathway, proteolysis, negative regulation of endopeptidase activity, cell adhesion, complement activation,

glycosaminoglycan catabolic process, regulation of immune response, blood $\mathrm{mg}$ (first day); coagulation, complement activation and classical pathway, negative regulation cisplatin: $132 \mathrm{mg}$ of cell adhesion, cellular amino acid metabolic process, negative regulation of (first day)

fibrinolysis, carbohydrate metabolic process, oxidation-reduction process, retinoid metabolic process, leukocyte migration, acute-phase response, metabolic process, immune response, positive regulation of $\mathrm{T}$ cell proliferation, cell-cell adhesion

T2:cell-cell adhesion, proteolysis, proteolysis involved in cellular protein catabolic process, platelet degranulation,, glycosaminoglycan catabolic process, regulation of complement activation, blood coagulation, metabolic process, leukocyte migration, cell adhesion, negative regulation of endopeptidase

Pemetrexed:881 activity, oxidation-reduction process, canonical glycolysis, gluconeogenesis,
$\mathrm{T} 2$

2019.01.04

$\mathrm{mg}$ (first day);

cisplatin: $132 \mathrm{mg}$ (first day)

Pemetrexed:881 $\mathrm{mg}$ (first day)
54.6 Yes Stable disease complement activation and alternative pathway, carbohydrate metabolic

process, tumor necrosis factor-mediated signaling pathway, ATP metabolic process, glutathione biosynthetic process, glycolytic process, complement activation, acute-phase response, Wnt signaling pathway, planar cell polarity pathway, cellular amino acid metabolic process, regulation of immune response, negative regulation of cell adhesion, NIK/NF-kappaB signaling, glucose metabolic process, complement activation and classical pathway

T3: cell-cell adhesion, oxidation-reduction process, cellular amino acid metabolic process, platelet degranulation, carbohydrate metabolic process, proteolysis, NIK/NF-kappaB signaling, Wnt signaling pathway and planar cell polarity pathway, canonical glycolysis, tumor necrosis factor-mediated signaling pathway, gluconeogenesis, negative regulation of endopeptidase activity, Fcepsilon receptor signaling pathway, glucose metabolic process, proteolysis involved in cellular protein catabolic process, glycolytic process, T cell receptor signaling pathway, metabolic process, blood coagulation, cell adhesion, Fcgamma receptor signaling pathway involved in phagocytosis, innate immune response, regulation of complement activation, complement activation and alternative pathway 
A

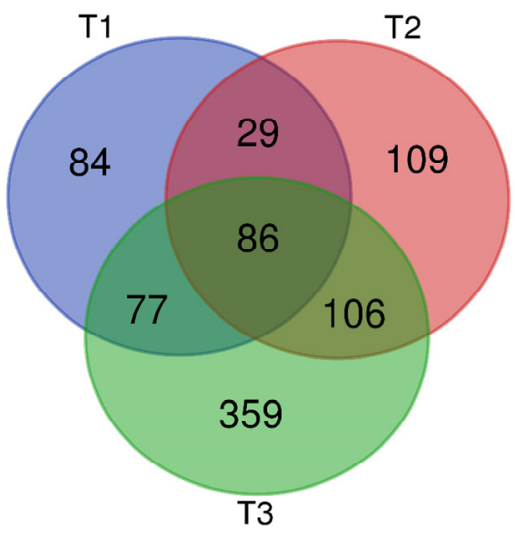

B

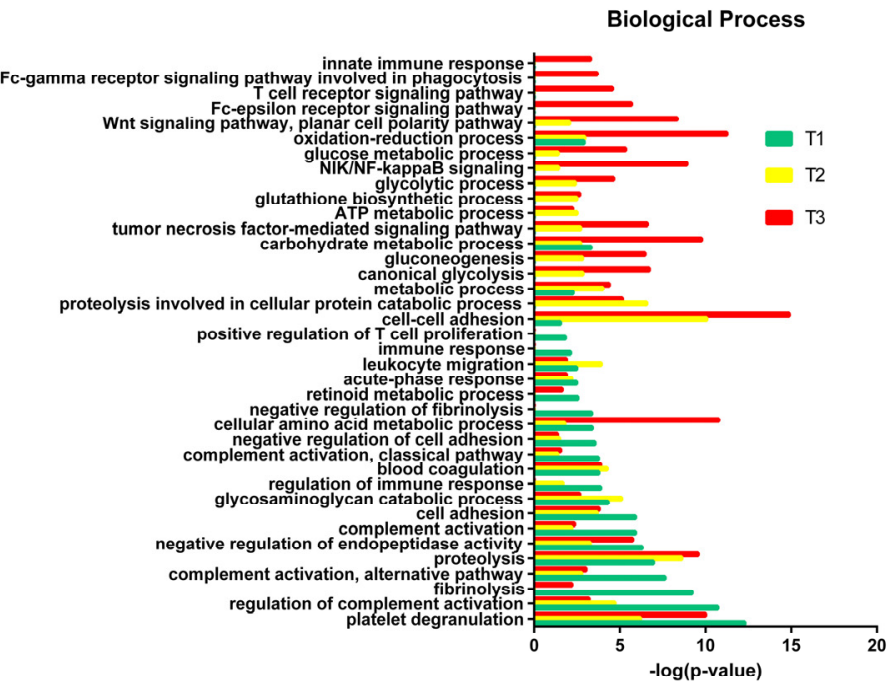

The changed biological processes at the three time points show that during the overall treatment process, immune-related biological processes changed significantly. The changes reflected by urinary protein are consistent with a partial response. This indicates that the combination of these drugs (pemetrexed and cisplatin) had a good therapeutic effect in patient P6.

Changes in the urine proteome and functional analysis in patient $\mathrm{P7}$. The urine samples of patient P7 at two time points before and after drug treatment were collected and analyzed. More details about the urine samples and the clinical symptoms of the patient are shown in Table 7. Compared to those seen before drug treatment, a total of 1,215 urinary proteins were identified. After the screening, 212 differential urinary proteins were identified (Table 1).

The differential proteins were analyzed by the DAVID database and classified based on biological processes. Changes in biological processes are shown in Table 8 and Fig. 7. Unlike 
351 other patients, patient P7 developed symptoms of severe fever and pneumonia after the initial

352 treatment and died a few days later. The patient's death may have been caused by adverse events

353 following treatment with sintilimab. Sintilimab is a human immunoglobulin G4 monoclonal

354 antibody that specifically binds PD-1 molecules on the surface of T cells, thereby activating

355 lymphocytes to treat tumors. However, a variety of immune-related adverse events (irAEs) may

356 also occur during treatment with similar drugs, such as immune-related pneumonia, myocarditis,

357 nephritis, renal insufficiency, and hepatitis [42]. There have been reports of three cases of fatal

358 pneumonia with such drugs in clinical trials [43]. Of all the biological process affected, as

359 reflected by changed urinary proteins, platelet degranulation, gluconeogenesis, leukocyte

360 migration, retinoid metabolic processes, cell adhesion, movement of cell or subcellular

361 component, negative regulation of endopeptidase activity, extracellular matrix organization,

362 cellular response to tumor necrosis factor, and glycosaminoglycan catabolic process changed

363 most significantly.

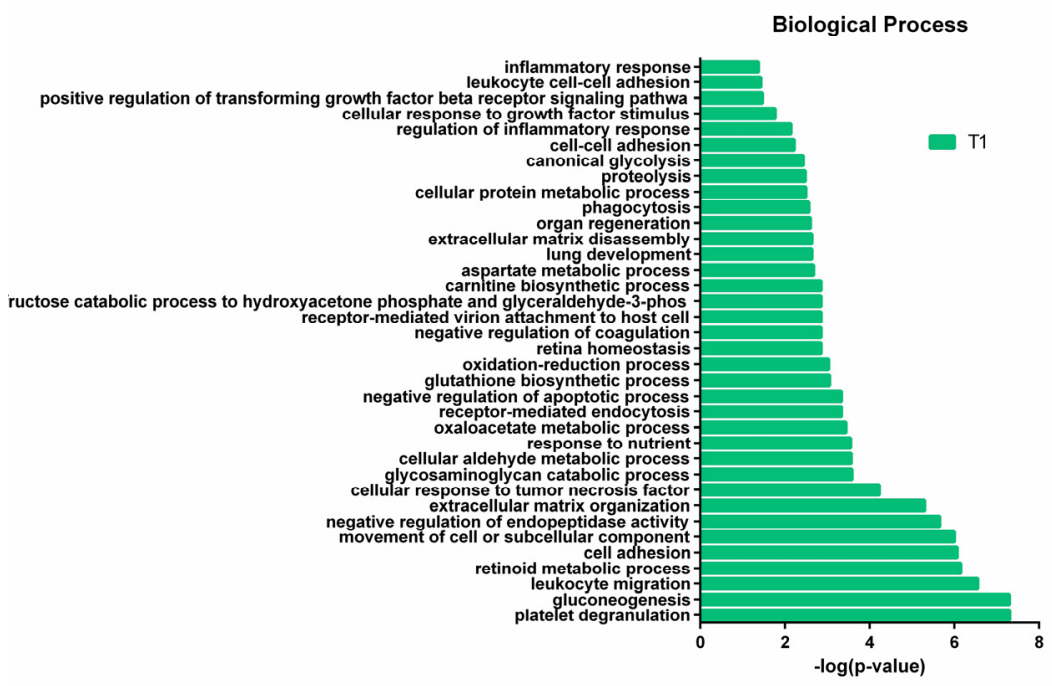

365 Fig. 7 Biological processes of differential proteins in patient P7. 


\begin{tabular}{|c|c|c|c|c|c|c|}
\hline $\begin{array}{l}\text { Urine } \\
\text { collection } \\
\text { time }\end{array}$ & $\begin{array}{l}\text { Target } \\
\text { focus } \\
\text { length } \\
(\mathrm{mm})\end{array}$ & $\begin{array}{l}\text { Non- } \\
\text { target } \\
\text { focus }\end{array}$ & $\begin{array}{l}\text { Clinical } \\
\text { manifestations }\end{array}$ & $\begin{array}{l}\text { Treatment } \\
\text { duration }\end{array}$ & Medication use & Biological processes change significantly (in part) \\
\hline $\begin{array}{l}\text { Control } \\
(2018.11 .20)\end{array}$ & 15.2 & Yes & Baseline & None & None & None \\
\hline $\begin{array}{l}\text { T1 } \\
(2018.12 .11)\end{array}$ & & - & Death & 2018.11 .20 & $\begin{array}{l}\text { Pemetrexed: } 866 \mathrm{mg} \text {, carboplatin: } \\
\text { 629mg, sintilimab: } 200 \mathrm{mg}\end{array}$ & $\begin{array}{l}\text { T1: platelet degranulation, gluconeogenesis, leukocyte } \\
\text { migration, retinoid metabolic process, cell adhesion, } \\
\text { movement of cell or subcellular component, negative } \\
\text { regulation of endopeptidase activity, extracellular matrix } \\
\text { organization, cellular response to tumor necrosis factor, } \\
\text { glycosaminoglycan catabolic process, cellular aldehyde } \\
\text { metabolic process, response to nutrient, oxaloacetate } \\
\text { metabolic process, receptor-mediated endocytosis, } \\
\text { negative, regulation of apoptotic process, glutathione } \\
\text { biosynthetic process, oxidation-reduction process, retina } \\
\text { homeostasis, negative regulation of coagulation, receptor- } \\
\text { mediated virion attachment to host cell, fructose catabolic } \\
\text { process to hydroxyacetone phosphate and glyceraldehyde- } \\
\text { 3-phosphate, } \\
\text { carnitine biosynthetic process, aspartate metabolic process, } \\
\text { lung development, extracellular matrix disassembly, organ } \\
\text { regeneration, phagocytosis, cellular protein metabolic } \\
\text { process, proteolysis, canonical glycolysis }\end{array}$ \\
\hline
\end{tabular}


The patient experienced severe adverse reactions after a period of treatment with sintilimab, pemetrexed, and carboplatin, but significant changes in a large number of immune and cytokinerelated biological processes were not observed in the urine samples collected after symptoms appeared. It is speculated that the reason may be that the occurrence of irAEs was very sudden and rapid. Prior to this, the biological processes in the body were still in a relatively normal state, and the urine proteome in patient $\mathrm{P} 7$ was not affected.

\section{Changes in the urine proteome and functional analysis in patient $\mathbf{P 8}$. The urine samples of} patient P8 at three time points before and after drug treatment were collected and analyzed. More details about the urine samples and the clinical symptoms of the patient are shown in Table 9. Compared to those seen before drug treatment, a total of 1,248 urinary proteins were identified. After the screening, 408 differential urinary proteins were identified, of which 194 and 329 were identified at the time points $\mathrm{T} 1$ and $\mathrm{T} 2$, respectively (Table 2). A Venn diagram showed overlapping differential urinary proteins at two time points (Fig. 8A). One hundred and fifteen proteins changed at both time points, and 79 and 214 unique differential urinary proteins changed at the $\mathrm{T} 1$ and $\mathrm{T} 2$ time points, respectively.

The differential proteins identified at the $\mathrm{T} 1$ and $\mathrm{T} 2$ time points were analyzed by the DAVID database and classified based on biological processes. Changes in biological processes are shown in Table 9 and Fig. 8B. Some common biological processes were significantly affected, such as negative regulation of endopeptidase activity, platelet degranulation, glycosaminoglycan catabolism, cellular protein metabolic process, fibrinolysis, carbohydrate metabolism process, positive regulation of nitric oxide biosynthesis process, gluconeogenesis, canonical glycolysis, glycolysis process, proteolysis, retinoid metabolism process, cell-cell 
391 adhesion, glycosaminoglycan metabolism process, glutathione metabolism process, acute phase 392 response, ATP biosynthesis process, complement activation and classical pathway, complement 393 activation and alternative pathway, complement activation, leukocyte cell-cell adhesion, and regulation of complement activation. These biological processes included immune responses and reactions related to tumor growth. At the T1 time point, some metabolic-related biological

396 processes were significantly affected, and other biological processes related to the immune 397 response were also affected. At that time, the patient was evaluated as having stable disease. At 398 the T2 time point, the degree of change in biological processes related to tumor growth was 399 significant and was higher than the degree of changes in biological processes related to 400 immunology. Meanwhile, the number of changes immunologically related biological processes 401 was large. The patient was evaluated as having stable disease.

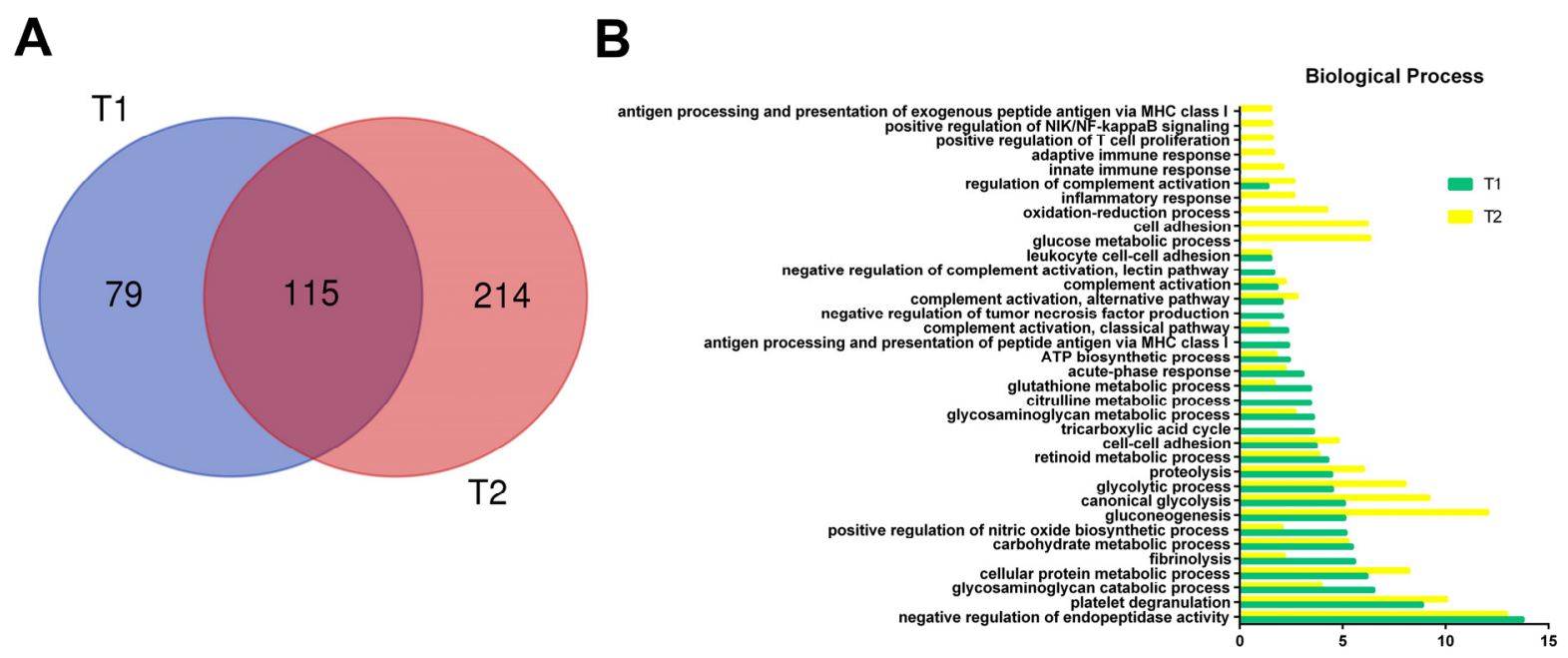

403 Fig. 8 Proteomic analysis of urine samples in patient P8. A, overlap evaluation of the differential proteins 404 identified at two time points, T1 and T2. B, biological processes of differential proteins at two time points $405 \quad \mathrm{~T} 1$ and $\mathrm{T} 2$. 
Table 9. The clinical information of patient P8 and the changed biological processes at different time points.

\begin{tabular}{|c|c|c|c|c|c|c|}
\hline $\begin{array}{l}\text { Urine } \\
\text { collection } \\
\text { time }\end{array}$ & $\begin{array}{l}\text { Target } \\
\text { focus } \\
\text { length } \\
(\mathrm{mm})\end{array}$ & $\begin{array}{l}\text { Non- } \\
\text { target } \\
\text { focus }\end{array}$ & $\begin{array}{l}\text { Clinical } \\
\text { manifestations }\end{array}$ & $\begin{array}{l}\text { Treatment } \\
\text { duration }\end{array}$ & Medication use & Biological processes change significantly (in part) \\
\hline $\begin{array}{l}\text { Control } \\
(2019.01 .25)\end{array}$ & 110.4 & Yes & Baseline & None & None & None \\
\hline $\begin{array}{l}\text { T1 } \\
(2019.03 .09)\end{array}$ & 106.9 & Yes & Stable disease & 2019.02 .14 & $\begin{array}{l}\text { Pemetrexed and: } \\
\text { 906mg (first day); } \\
\text { cisplatin: 136mg } \\
\text { (first day) }\end{array}$ & $\begin{array}{l}\text { T1: negative regulation of endopeptidase activity, platelet } \\
\text { degranulation, glycosaminoglycan catabolic process, cellular protein } \\
\text { metabolic process, fibrinolysis, carbohydrate metabolic process, } \\
\text { positive regulation of nitric oxide biosynthetic process, } \\
\text { gluconeogenesis, canonical glycolysis, glycolytic process, } \\
\text { proteolysis, retinoid metabolic process, cell-cell adhesion, } \\
\text { tricarboxylic acid cycle, glycosaminoglycan metabolic process, } \\
\text { citrulline metabolic process, glutathione metabolic process, acute- } \\
\text { phase response, ATP biosynthetic process, antigen processing and } \\
\text { presentation of peptide antigen via MHC class I, complement } \\
\text { activation, classical pathway, negative regulation of tumor necrosis } \\
\text { factor production, complement activation and alternative pathway, } \\
\text { complement activation, negative regulation of complement } \\
\text { activation, lectin pathway, leukocyte cell-cell adhesion }\end{array}$ \\
\hline $\begin{array}{l}\text { T2 } \\
(2019.04 .09)\end{array}$ & 106.7 & Yes & Stable disease & 2019.03.29 & $\begin{array}{l}\text { Pemetrexed and: } \\
\text { 680mg (first day); } \\
\text { cisplatin: 136mg } \\
\text { (first day) }\end{array}$ & $\begin{array}{l}\text { T2:negative regulation of endopeptidase activity, gluconeogenesis, } \\
\text { platelet degranulation, canonical glycolysis, cellular protein } \\
\text { metabolic process, glycolytic process, glucose metabolic process, cell } \\
\text { adhesion, proteolysis, carbohydrate metabolic process, cell-cell } \\
\text { adhesion, oxidation-reduction process, glycosaminoglycan catabolic } \\
\text { process, retinoid metabolic process, complement activation, } \\
\text { alternative pathway, glycosaminoglycan metabolic process, } \\
\text { regulation of complement activation, inflammatory response, acute- } \\
\text { phase response, complement activation, fibrinolysis, innate immune } \\
\text { response, positive regulation of nitric oxide biosynthetic process, } \\
\text { ATP biosynthetic process, glutathione metabolic process, adaptive } \\
\text { immune response, positive regulation of T cell proliferation, positive } \\
\text { regulation of NIK/NF-kappaB signaling, leukocyte cell-cell } \\
\text { adhesion, antigen processing and presentation of exogenous peptide } \\
\text { antigen via MHC class II }\end{array}$ \\
\hline
\end{tabular}


The significantly affected biological process at two time points show that during the

411 treatment process, the changes in the metabolic biological processes of tumors were more

412 significant than the changes in other processes; this is consistent with the clinical assessment of

413 the patient, which indicated that combination treatment with pemetrexed and cisplatin had an

414 effect in patient P8. This is consistent with the evaluation of stable disease, and the efficacy of

415 the drug may require follow-up observation.

\section{Methods}

418 Ethics statement. This study was approved by the Ethics Committee of Peking Union Medical

419 College Hospital. All methods used in this protocol were carried out in accordance with relevant 420 guidelines and regulations. All participants signed informed consent forms.

422 Patient samples. A total of 23 urine samples were collected from 8 patients with advanced lung

423 cancer (patients with unresectable stage IIIB-IV lung cancer) from Peking Union Medical

424 College Hospital. The clinical data of all patients are summarized in Table 10. Lung cancer

425 staging was based on the eighth edition of the International Lung Cancer TNM Staging

426 Standard $^{37}$. RECIST 1.1 were used to evaluate responses ${ }^{38}$.

427 Table 10 Clinical profiles of patients with advanced lung cancer.

\begin{tabular}{|c|c|c|c|c|}
\hline $\begin{array}{l}\text { Patient } \\
\text { ID }\end{array}$ & Age, years & Sex & Type of lung cancer & $\begin{array}{l}\text { Clinical } \\
\text { stage }\end{array}$ \\
\hline P1 & 53 & Male & Lung adenocarcinoma & IVA \\
\hline $\mathrm{P} 2$ & 62 & Male & $\begin{array}{l}\text { Infiltrating adenocarcinoma of the upper left } \\
\text { lung }\end{array}$ & IVA \\
\hline P3 & 83 & Male & $\begin{array}{l}\text { Differentiated squamous cell carcinoma in } \\
\text { the right lung }\end{array}$ & IIIB \\
\hline P4 & 53 & Male & $\begin{array}{l}\text { Differentiated squamous cell carcinoma of } \\
\text { the left lung }\end{array}$ & IIIB \\
\hline P5 & 64 & Male & Large cell neuroendocrine carcinoma & IIIB \\
\hline P6 & 59 & Female & Adenocarcinoma of the right upper lung & IVA \\
\hline
\end{tabular}




\begin{tabular}{lllll}
\hline P7 & 70 & Female & Lung poorly differentiated adenocarcinoma & IVA \\
P8 & 64 & Male & Lung adenocarcinoma & IVA \\
\hline
\end{tabular}

Sample preparation. Urine samples were collected at different time points after different drug treatments from all patients. In addition, the control samples were collected from patients at the time they were diagnosed with advanced lung cancer and had not received treatment. All samples were morning and midstream urine samples. After collection, urine samples were centrifuged to remove cell debris and impurities and temporarily stored in a $-80^{\circ} \mathrm{C}$ refrigerator for later use. LC-MS/MS analysis was conducted. Briefly, $20 \mathrm{ml}$ urine was thawed and centrifuged at 12,000 g for 30 minutes, and then the supernatants were transferred and mixed with three volumes of precooled ethanol in a refrigerator at $-20^{\circ} \mathrm{C}$ for 12 hours. The supernatant was discarded, the precipitates were dried, and lysis buffer $(8 \mathrm{~mol} / \mathrm{L}$ urea, $2 \mathrm{~mol} / \mathrm{L}$ thiourea, 50 $\mathrm{mmol} / \mathrm{L}$ Tris, and $25 \mathrm{mmol} / \mathrm{L}$ dithiothreitol) was added until the precipitates were dissolved. After centrifugation, the supernatant was retained and measured by Bradford assay. The FASP method was used to digest all the protein samples ${ }^{39}$. One hundred micrograms of each sample was added to a $10 \mathrm{kDa}$ filter (Pall, Port Washington, NY, USA), and then the urea buffer solution (UA, $8 \mathrm{~mol} / \mathrm{L}$ urea and $0.1 \mathrm{~mol} / \mathrm{L}$ Tris- $\mathrm{HCl}, \mathrm{pH} 8.5$ ) and the $25 \mathrm{mmol} / \mathrm{L} \mathrm{NH} 4 \mathrm{HCO} 3$ solution were added sequentially to wash the urinary protein several times. Then, $100 \mu 1 \mathrm{NH} 4 \mathrm{HCO} 3$ solution and dithiothreitol (final concentration was $20 \mathrm{mmol} / \mathrm{L}$ ) were added and incubated at 37 ${ }^{\circ} \mathrm{C}$ for 1 hour. Combined with the $100 \mu \mathrm{NH} 4 \mathrm{HCO} 3$ solution, iodoacetamide (final concentration was $50 \mathrm{mmol} / \mathrm{L}$ ) was added, and the mixture was placed in the dark for 30 minutes. After centrifugation at $14,000 \mathrm{~g}$ for 40 minutes, the UA solution and $\mathrm{NH} 4 \mathrm{HCO} 3$ solution were again used to wash the protein several times. Then, trypsin was added to the protein (the ratio of enzyme to protein was 1:50) and mixed, and the protein was digested at $37^{\circ} \mathrm{C}$ overnight. After 
centrifugation at $14,000 \mathrm{~g}$ for 40 minutes, the filtrate was the peptide mixture. The peptide mixture was desalted with Oasis HLB cartridges (Waters, Milford, MA), evaporated to dryness in vacuo and diluted to $0.5 \mu \mathrm{g} / \mu \mathrm{L}$ with $0.1 \%$ formic acid (FA). The concentrations were determined by a BCA assay.

LC-MS/MS analysis. Two microliters of the peptide from each sample was loaded into a trap column at a flow rate of $0.3 \mathrm{ml} / \mathrm{min}$ and then separated with a reverse-phase $\mathrm{C} 18$ analytical column. Peptides were eluted with a gradient extending from $4 \%$ to $28 \%$ buffer B $(0.1 \%$ formic acid in $80 \%$ acetonitrile) for 90 min and then analyzed with an Orbitrap Fusion Lumos Tribrid Mass Spectrometer (Thermo Fisher Scientific, USA). The MS data were acquired using the following parameters: spray voltage was $2.4 \mathrm{kV}$; ion transfer tube temperature was $320^{\circ} \mathrm{C}$; firstlevel full scan was set to $350-1,550 \mathrm{~m} / \mathrm{z}$, resolution was 60,000 ; secondary scan was set to 200 $2,000 \mathrm{~m} / \mathrm{z}$, resolution was 30,000 ; cycle time was $3 \mathrm{~s}$; and $\mathrm{HCD}$ collision energy was $30 \%$. Each peptide sample was analyzed three times.

The raw data collected by the mass spectrometer were analyzed by Proteome Discoverer software (version 2.1, Thermo Fisher) to convert the format. All data files were searched using Mascot software (version 2. 4.1; Matrix Science, UK) against the SwissProt database (taxonomy: Homo; containing 20,346 sequences). The search criteria included trypsin digestion; the parent ion tolerance was $10 \mathrm{ppm}$; the fragment ion mass tolerance was $0.02 \mathrm{Da}$; two missed trypsin cleavage sites were allowed; the carbamidomethylation of cysteine was set as a fixed modification; and the oxidation of methionine was considered a variable modification. After the retrieval was completed, all the dat files were exported and processed using Scaffold software (version 4.7.5, Proteome Software Inc., Portland, OR). The parameters were set as follows: both 
473 protein and peptide identifications were accepted at a false discovery rate (FDR) of less than 1\%;

474 each protein contained at least 2 unique peptides; different samples were performed after

475 normalization of total spectra; and spectral counting was used to compare protein abundance at

476 different time points according to previously described procedures ${ }^{40,41}$.

478 Statistical analysis. For each sample, three technical replicates were performed for statistical 479 analysis. Urine samples from before and after treatment were compared for each patient. The 480 selected criteria of differential urinary proteins were set as follows: fold change $\geq 2$ or $\leq 0.5$; and

481 P-value $<0.05$. Comparisons between two time points were conducted using a two-sided paired t482 test. The statistical analysis was performed with GraphPad Prism version 7.0 (GraphPad, San 483 Diego, CA) software. The differential proteins were analyzed by DAVID 6.8

484 (https://david.ncifcrf.gov/). The proteins were described according to biological processes. 485

\section{Conclusion}

487 In this study, patients with advanced lung cancer were treated with different drugs and their urine 488 proteomes were compared before and after treatment. It was found that pathophysiological 489 changes in patients with advanced lung cancer could be reflected by changes in urinary protein 490 after different drug treatments. In addition, the changes in urinary protein could reflect different 491 biological processes in patients after the same drug treatment, and the clinical condition of 492 patients was consistent with these changes. These findings may provide additional information 493 for clinical treatment.

\section{Data availability}


496 All the data supporting the findings of this study are available within the article and its

497 supplementary information files and from the corresponding authors upon reasonable request. 


\section{References}

$4991 \quad$ Bray, F. et al. Global cancer statistics 2018: GLOBOCAN estimates of incidence and 500 mortality worldwide for 36 cancers in 185 countries. CA Cancer J Clin 68, 394-424, doi:10.3322/caac.21492 (2018).

2 Torre, L. A., Siegel, R. L., Ward, E. M. \& Jemal, A. Global Cancer Incidence and Mortality Rates and Trends--An Update. Cancer Epidemiol Biomarkers Prev 25, 16-27, doi:10.1158/1055-9965.EPI-15-0578 (2016).

3 Torre, L. A., Siegel, R. L. \& Jemal, A. Lung Cancer Statistics. Adv Exp Med Biol 893, 119, doi:10.1007/978-3-319-24223-1_1 (2016).

4 Miller, K. D. et al. Cancer treatment and survivorship statistics, 2016. CA Cancer J Clin 66, 271-289, doi:10.3322/caac.21349 (2016).

5 Lemjabbar-Alaoui, H., Hassan, O. U., Yang, Y. W. \& Buchanan, P. Lung cancer: Biology and treatment options. Biochim Biophys Acta 1856, 189-210, doi:10.1016/j.bbcan.2015.08.002 (2015).

6 Vasconcellos, V. F. et al. Cisplatin versus carboplatin in combination with thirdgeneration drugs for advanced non-small cell lung cancer. Cochrane Database Syst Rev 1, CD009256, doi:10.1002/14651858.CD009256.pub3 (2020).

7 Seto, T. et al. Erlotinib alone or with bevacizumab as first-line therapy in patients with advanced non-squamous non-small-cell lung cancer harbouring EGFR mutations (JO25567): an open-label, randomised, multicentre, phase 2 study. Lancet Oncol 15, 1236-1244, doi:10.1016/S1470-2045(14)70381-X (2014).

8 Laskin, J. et al. Safety and efficacy of first-line bevacizumab plus chemotherapy in elderly patients with advanced or recurrent nonsquamous non-small cell lung cancer: safety of avastin in lung trial (MO19390). J Thorac Oncol 7, 203-211, doi:10.1097/JTO.0b013e3182370e02 (2012).

9 Tassinari, D. et al. Bevacizumab in the treatment of advanced, non-squamous non-small cell lung cancer: an evidence-based approach. Oncology 80, 350-358, doi:10.1159/000328781 (2011).

10 La-Beck, N. M., Nguyen, D. T., Le, A. D., Alzghari, S. K. \& Trinh, S. T. Optimizing Patient Outcomes with PD-1/PD-L1 Immune Checkpoint Inhibitors for the First-Line Treatment of Advanced Non-Small Cell Lung Cancer. Pharmacotherapy, doi:10.1002/phar.2364 (2020).

11 Herbst, R. S. et al. Pembrolizumab versus docetaxel for previously treated, PD-L1positive, advanced non-small-cell lung cancer (KEYNOTE-010): a randomised controlled trial. Lancet 387, 1540-1550, doi:10.1016/S0140-6736(15)01281-7 (2016).

12 YouHe, G. Urine - an untapped goldmine for biomarker discovery? Science China (Life Sciences), 10 (2013).

13 Zhao, M., Wu, J., Li, X. \& Gao, Y. Urinary candidate biomarkers in an experimental autoimmune myocarditis rat model. $J$ Proteomics 179, 71-79, doi:10.1016/j.jprot.2018.02.032 (2018).

14 Zhang, F., Wei, J., Li, X., Ma, C. \& Gao, Y. Early Candidate Urine Biomarkers for Detecting Alzheimer's Disease Before Amyloid-beta Plaque Deposition in an APP (swe)/PSEN1dE9 Transgenic Mouse Model. $J$ Alzheimers Dis 66, 613-637, doi:10.3233/JAD-180412 (2018).

15 Zhang, F., Ni, Y., Yuan, Y., Yin, W. \& Gao, Y. Early urinary candidate biomarker 
discovery in a rat thioacetamide-induced liver fibrosis model. Science China Life Sciences 61, 1369-1381 (2018).

16 Ni, Y., Zhang, F., An, M., Yin, W. \& Gao, Y. Early candidate biomarkers found from urine of glioblastoma multiforme rat before changes in MRI. Sci China Life Sci 61, 982-987, doi:10.1007/s11427-017-9201-0 (2018).

$17 \mathrm{Wu}, \mathrm{J} ., \mathrm{Li}, \mathrm{X} . \&$ Gao, Y. Early detection in urinary proteome for the effective early treatment of bleomycin-induced pulmonary fibrosis in a rat model. Proteomics Clin Appl 11, 11-12 (2017).

18 Zhang, L., Li, Y. \& Gao, Y. Early changes in the urine proteome in a diethyldithiocarbamate-induced chronic pancreatitis rat model. Journal of proteomics 186 , 8-14 (2018).

19 Yameng, Z., Yufei, G. \& Youhe, G. Early changes in the urine proteome in a rat liver tumor model. bioRxiv, 568246 (2019).

20 Zhang, L., Li, Y., Meng, W., Ni, Y. \& Gao, Y. Dynamic urinary proteomic analysis in a Walker 256 intracerebral tumor model. Cancer Med 8, 3553-3565, doi:10.1002/cam4.2240 (2019).

21 Gao, Y. Urine: Promising Biomarker Source for Early Disease Detection. (Springer, 2019).

22 Grasmann, G., Smolle, E., Olschewski, H. \& Leithner, K. Gluconeogenesis in cancer cells - Repurposing of a starvation-induced metabolic pathway? Biochim Biophys Acta Rev Cancer 1872, 24-36, doi:10.1016/j.bbcan.2019.05.006 (2019).

23 Kubes, P. The enigmatic neutrophil: what we do not know. Cell Tissue Res 371, 399-406, doi:10.1007/s00441-018-2790-5 (2018).

24 Chaturvedi, S., Hoffman, R. M. \& Bertino, J. R. Exploiting methionine restriction for cancer treatment. Biochem Pharmacol 154, 170-173, doi:10.1016/j.bcp.2018.05.003 (2018).

25 Chen, K. et al. Genetic variants in RUNX3, AMD1 and MSRA in the methionine metabolic pathway and survival in nonsmall cell lung cancer patients. Int $J$ Cancer 145, 621-631, doi:10.1002/ijc.32128 (2019).

26 Yang, M. \& Vousden, K. H. Serine and one-carbon metabolism in cancer. Nat Rev Cancer 16, 650-662, doi:10.1038/nrc.2016.81 (2016).

27 Cavallaro, U. \& Christofori, G. Cell adhesion in tumor invasion and metastasis: loss of the glue is not enough. Biochim Biophys Acta 1552, 39-45, doi:10.1016/s0304419x(01)00038-5 (2001).

28 Lawrence, T., Gilroy, D. W., Colville-Nash, P. R. \& Willoughby, D. A. Possible new role for NF-kappaB in the resolution of inflammation. Nat Med 7, 1291-1297, doi:10.1038/nm1201-1291 (2001).

29 Duchartre, Y., Kim, Y. M. \& Kahn, M. The Wnt signaling pathway in cancer. Crit Rev Oncol Hematol 99, 141-149, doi:10.1016/j.critrevonc.2015.12.005 (2016).

30 Yang, Y., Sun, M., Wang, L. \& Jiao, B. HIFs, angiogenesis, and cancer. J Cell Biochem 114, 967-974, doi:10.1002/jcb.24438 (2013).

31 Perrotta, C. et al. Nitric Oxide Generated by Tumor-Associated Macrophages Is Responsible for Cancer Resistance to Cisplatin and Correlated With Syntaxin 4 and Acid Sphingomyelinase Inhibition. Front Immunol 9, 1186, doi:10.3389/fimmu.2018.01186 (2018).

32 Dobrotkova, V., Chlapek, P., Mazanek, P., Sterba, J. \& Veselska, R. Traffic lights for 


\section{Acknowledgements}

This work was supported by National Key Research and Development Program of China (2018YFC0910202, 2016YFC1306300), the Fundamental Research Funds for the Central Universities (2020KJZX002), Beijing Natural Science Foundation (7172076), Beijing cooperative construction project (110651103), Beijing Normal University (11100704), Peking Union Medical College Hospital (2016-2.27), CAMS Initiative for Innovative Medicine (No. 2017-I2M-4-002; No. 2016-I2M-1-001), PUMC Youth Fund (No.2017320001), National 


\section{Author contributions}

626 Z.Y.M., W.Y.Y and G.Y.H. conceived and designed the experiments; Z.Y.M and H.Z.Q

627 performed the experiments; Z.Y.M., H.Z.Q and W.J. analyzed the data, Z.Y.M. wrote the paper.

628

629 Competing interests

630 All the authors declare no competing interests.

631

632 


\section{Figure legends}

634 Fig. 1 Proteomic analysis of urine samples in patient P1. A, overlap evaluation of the differential 635 proteins identified at three time points, $\mathrm{T} 1, \mathrm{~T} 2$, and $\mathrm{T} 3$. B, biological processes of differential 636 proteins at three time points, $\mathrm{T} 1, \mathrm{~T} 2$ and $\mathrm{T} 3$.

637 Fig. 2 Proteomic analysis of urine samples in patient P2. A, overlap evaluation of the differential 638 proteins identified at three time points, $\mathrm{T} 1, \mathrm{~T} 2$, and $\mathrm{T} 3$. B, biological processes of differential 639 proteins at three time points $\mathrm{T} 1, \mathrm{~T} 2$ and $\mathrm{T} 3$.

640 Fig. 3 Biological processes of differential proteins in patient P3.

641 Fig. 4 Biological processes of differential proteins in patient P4.

642 Fig. 5 Biological processes of differential proteins in patient P5.

643 Fig. 6 Proteomic analysis of urine samples in patient P6. A, overlap evaluation of the differential 644 proteins identified at three time points, T1, T2, and T3. B, biological processes of differential 645 proteins at three time points $\mathrm{T} 1, \mathrm{~T} 2$ and $\mathrm{T} 3$.

646 Fig. 7 Biological processes of differential proteins in patient P7.

647 Fig. 8 Proteomic analysis of urine samples in patient P8. A, overlap evaluation of the differential 648 proteins identified at two time points, $\mathrm{T} 1$ and $\mathrm{T} 2$. B, biological processes of differential proteins 649 at two time points $\mathrm{T} 1$ and $\mathrm{T} 2$. 
651 Table 1 The number of urinary proteins identified in 8 patients.

652 Table 2 The clinical information of patient P1 and the changed biological processes at different

653 time points.

654 Table 3 The clinical information of patient P2 and the changed biological processes at different 655 time points.

656 Table 4 The clinical information of patient P3 and the changed biological processes.

657 Table 5 The clinical information of patient $\mathrm{P} 4$ and the changed biological processes.

658 Table 6 The clinical information of patient P5 and the changed biological processes.

659 Table 7 The clinical information of patient P6 and the changed biological processes at different 660 time points.

661 Table 8 The clinical information of patient P7 and the changed biological processes.

662 Table 9 The clinical information of patient P8 and the changed biological processes at different

663 time points.

664 Table 10 Clinical profiles of patients with advanced lung cancer. 
A

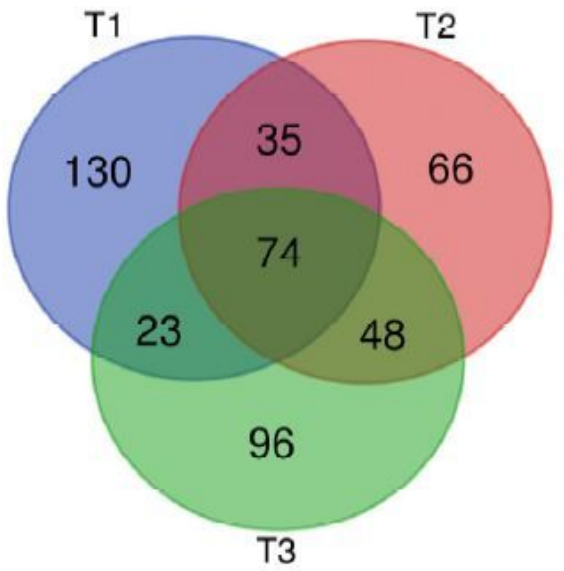

B

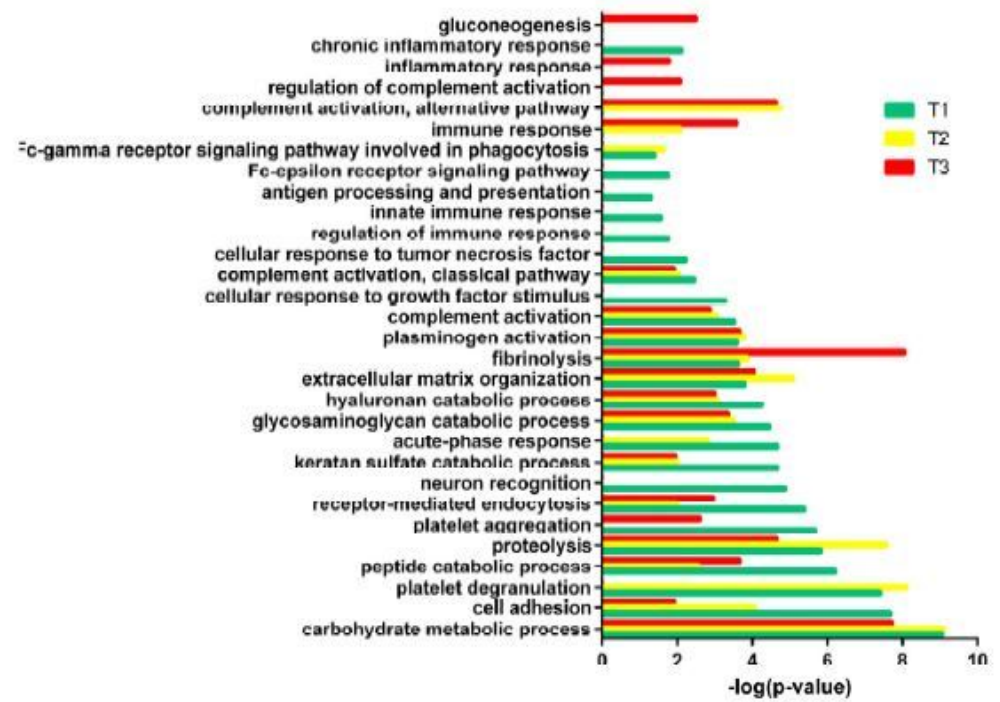

\section{Figure 1}

Proteomic analysis of urine samples in patient P1. A, overlap evaluation of the differential proteins identified at three time points, T1, T2, and T3. B, biological processes of differential proteins at three time points, T1, T2 and T3.

A

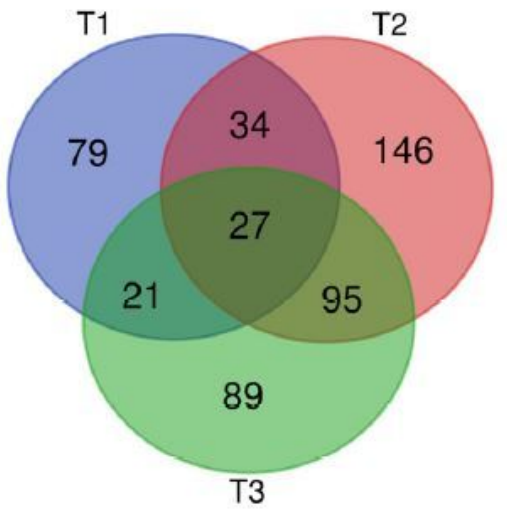

B

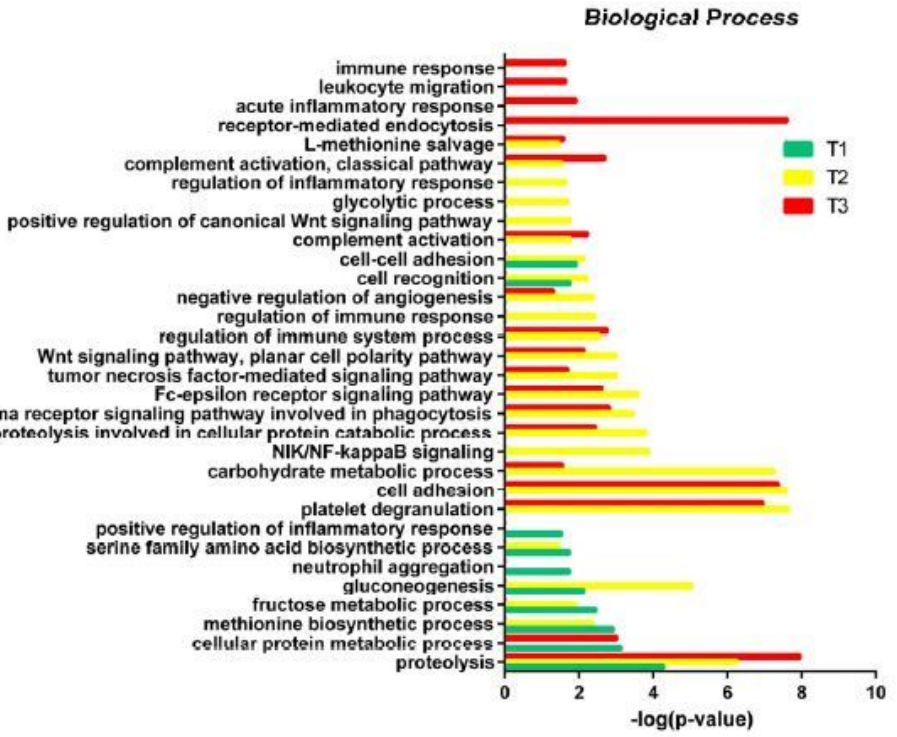

Figure 2 
Proteomic analysis of urine samples in patient P2. A, overlap evaluation of the differential proteins identified at three time points, T1, T2, and T3. B, biological processes of differential proteins at three time points T1, T2 and T3.

\section{Biological Process}

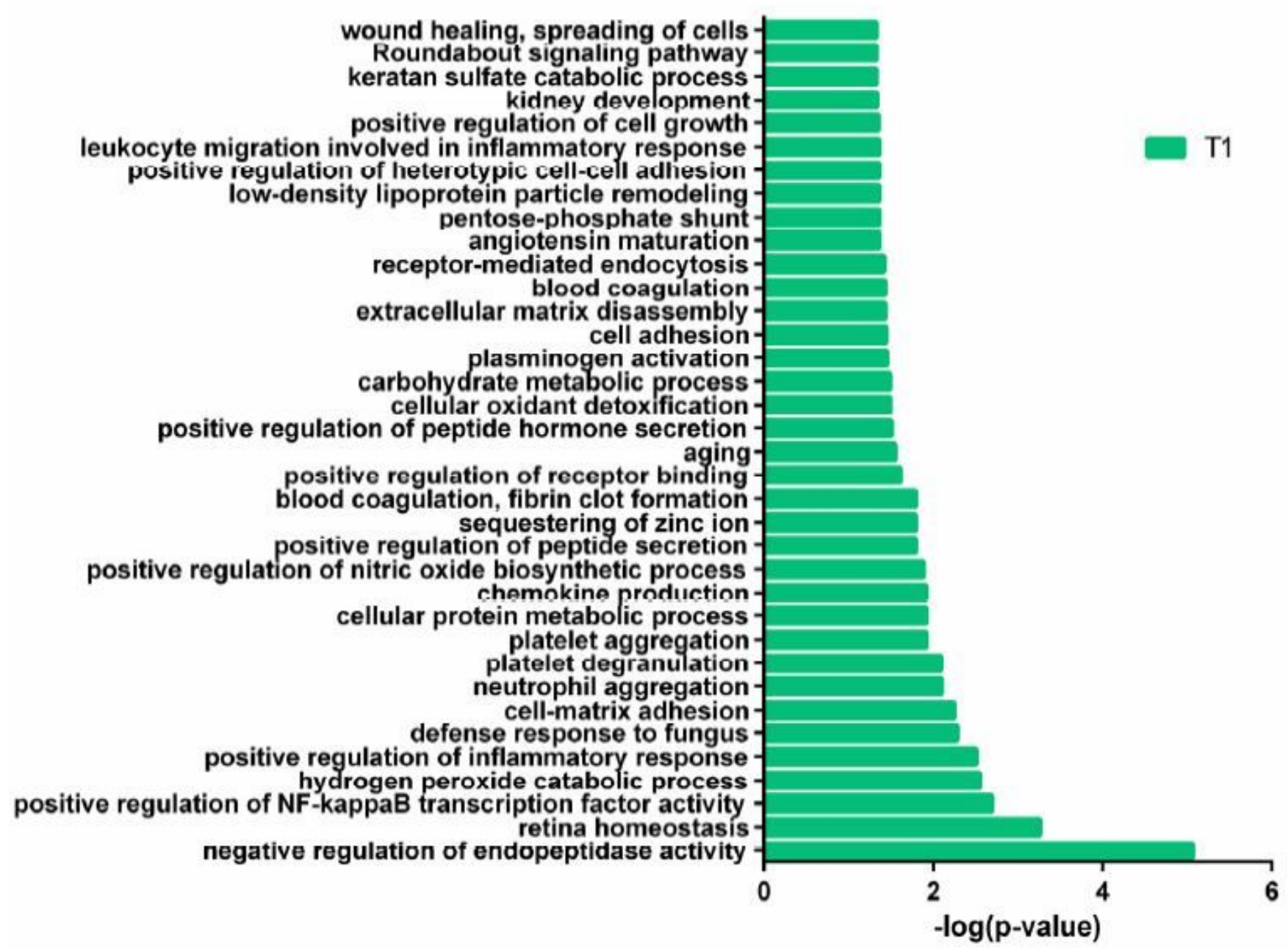

Figure 3

Biological processes of differential proteins in patient P3. 
Biological Process

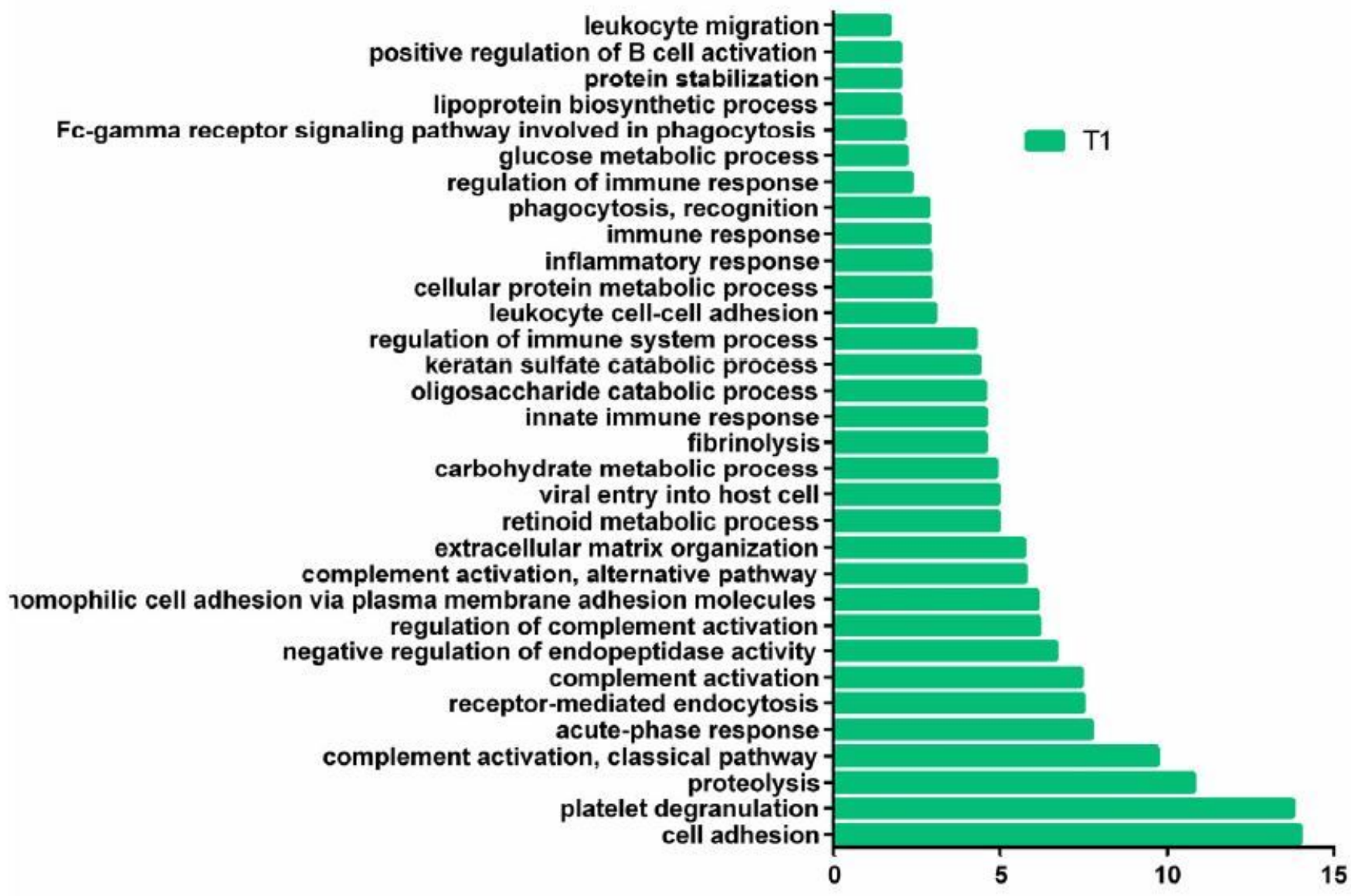

Figure 4

Biological processes of differential proteins in patient P4. 
Biological Process

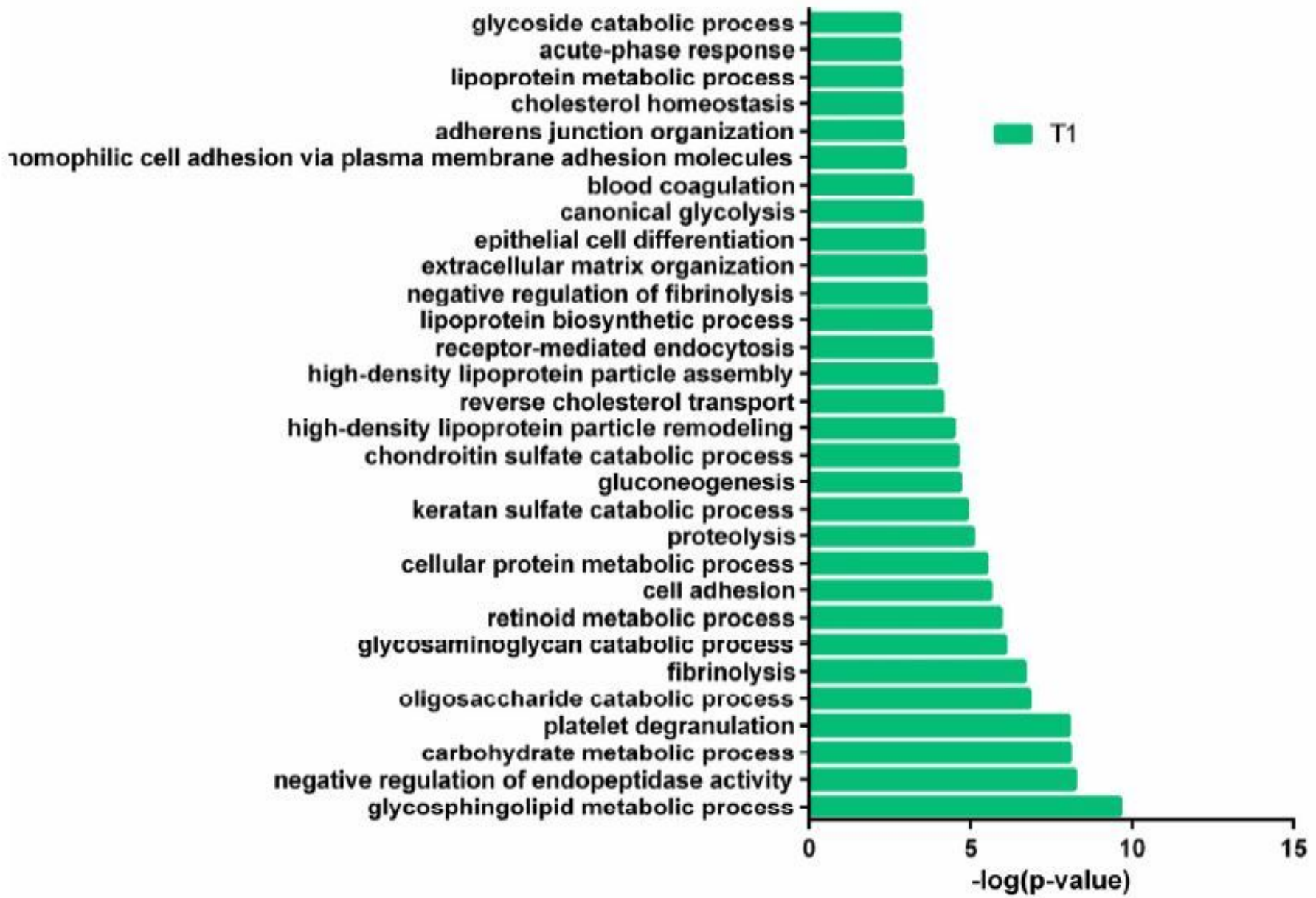

Figure 5

Biological processes of differential proteins in patient P5. 
A

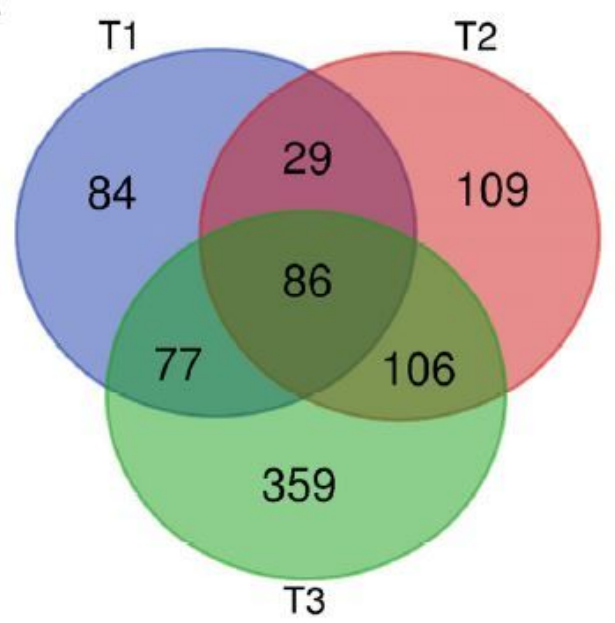

B

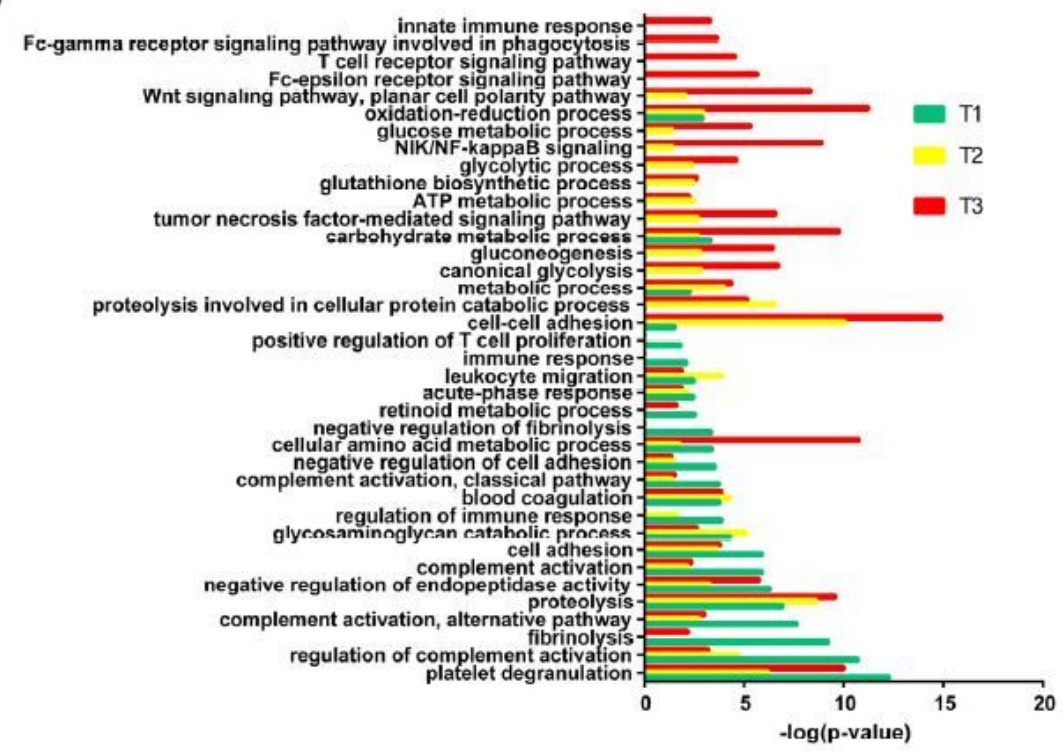

Figure 6

Proteomic analysis of urine samples in patient P6. A, overlap evaluation of the differential proteins identified at three time points, $\mathrm{T} 1, \mathrm{~T} 2$, and T3. B, biological processes of differential proteins at three time points $\mathrm{T} 1, \mathrm{~T} 2$ and $\mathrm{T} 3$. 


\section{Biological Process}

inflammatory response leukocyte cell-cell adhesion positive regulation of transforming growth factor beta receptor signaling pathwa cellular response to growth factor stimulus

regulation of inflammatory response cell-cell adhesion canonical glycolysis proteolysis phagocytosis organ regeneration extracellular matrix disassombly lung development aspartate metabolic process carnitine biosynthetic process ructose catabolic process to hydroxyacetone phosphate and glyceraldehyde-3-phos receptor-mediated virion attachment to host cell negative regulation of coagulation retina homeostasis oxidation-reduction process glutathione biosynthetic process negative regulation of apoptotic process receptor-mediated endocytosis oxaloacetate metabolic process response to nutrient cellular aldehyde metabolic process glycosaminoglycan catabolic process cellular response to tumor necrosis factor extracellular matrix organization negative regulation of endopeptidase activity movement of cell or subcellular component retinoid metabs cell adhesion leukocyte migration
gluconeogenesis platelet degranulation

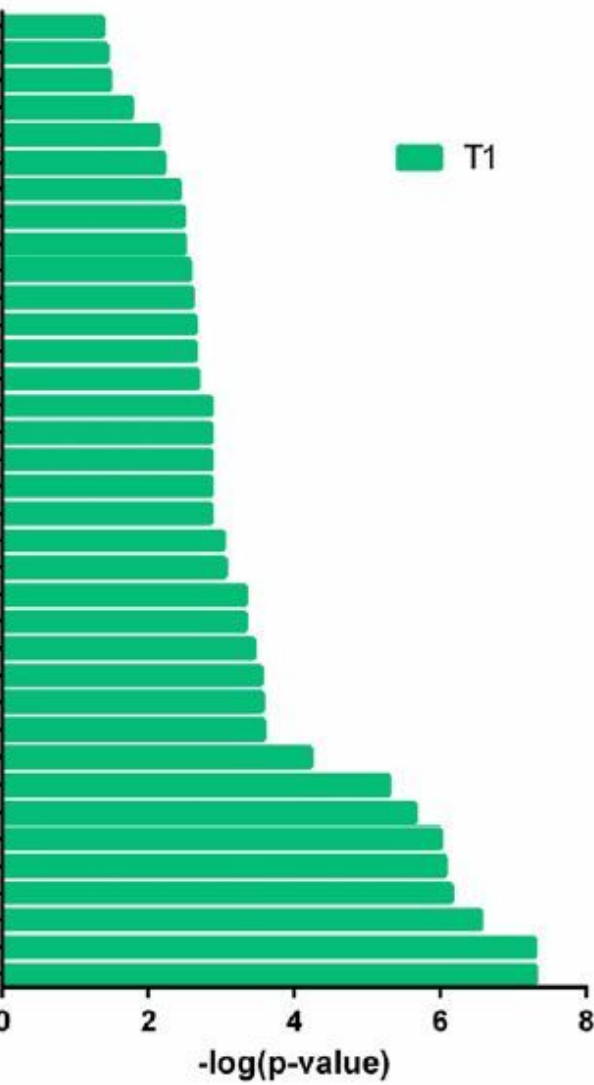

\section{Figure 7}

Biological processes of differential proteins in patient P7.

A

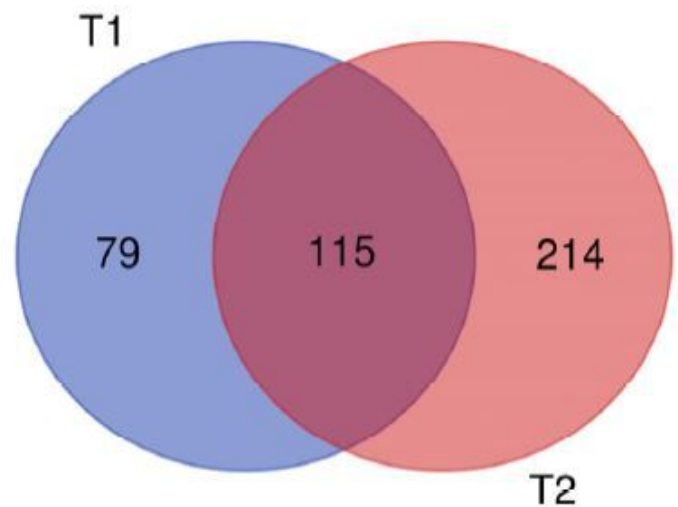

B

antigen processing and presentation of exogenous peptide antigen via MHC class I positive regulation of NIK/NF-kappaB signalin cell proliferatio regulation of complementent activation. oxidation-reduction rosponse oxidation red glucose motabolic process negative regulation of complement activation, lectin pathway complement activation, alternative pathway negative regulation of tumor neerosis foctor production
complement activation, classical pathway antigen processing and presentation of peptide antigen via MHC class
ATP biosynthetic process acute-phase respons glutathione motabolic process glycosaminoglycan metabolic process tricarboxylic acid cyclo retinoid motabolic process alycolytic process gluconeogenesis positive regulation of nitric oxide biosynthetic process
carbohydrate metabolic process carbonydrate metabolic process cellular protein metabolic process
glycosaminoglycan catabolic process negative regulation of endopeptidase activity 
Proteomic analysis of urine samples in patient P8. A, overlap evaluation of the differential proteins identified at two time points, T1 and T2. B, biological processes of differential proteins at two time points T1 and T2. 